\title{
Review Article \\ Electrochemical Reduction of Quinones in Different Media: A Review
}

\author{
Partha Sarathi Guin, ${ }^{1}$ Saurabh Das, ${ }^{2}$ and P. C. Mandal $^{3}$ \\ ${ }^{1}$ Department of Chemistry, Shibpur Dinobundhoo Institution (College), 412/1 G. T. Road (South), Howrah 711102, India \\ ${ }^{2}$ Department of Chemistry, Jadavpur University, Raja S. C. Mullick Road, Kolkata 700032, India \\ ${ }^{3}$ Chemical Sciences Division, Saha Institute of Nuclear Physics, 1/AF-Bidhannagar, Kolkata 700064, India \\ Correspondence should be addressed to Saurabh Das, dasrsv@yahoo.in
}

Received 27 August 2010; Accepted 10 December 2010

Academic Editor: Maria Carmen Arévalo

Copyright ( $\odot 2011$ Partha Sarathi Guin et al. This is an open access article distributed under the Creative Commons Attribution License, which permits unrestricted use, distribution, and reproduction in any medium, provided the original work is properly cited.

\begin{abstract}
The electron transfer reactions involving quinones, hydroquinones, and catechols are very important in many areas of chemistry, especially in biological systems. The therapeutic efficiency as well as toxicity of anthracycline anticancer drugs, a class of anthraquinones, is governed by their electrochemical properties. Other quinones serve as important functional moiety in various biological systems like electron-proton carriers in the respiratory chain and their involvement in photosynthetic electron flow systems. The present paper summarizes literatures on the reduction of quinones in different solvents under various conditions using different electrochemical methods. The influence of different reaction conditions including $\mathrm{pH}$ of the media, nature of supporting electrolytes, nature of other additives, intramolecular or intermolecular hydrogen bonding, ion pair formation, polarity of the solvents, stabilization of the semiquinone and quinone dianion, catalytic property, and adsorption at the electrode surface, are discussed and relationships between reaction conditions and products formed have been presented.
\end{abstract}

\section{Introduction}

Quinone-hydroquinone couples are the prototypical examples of organic redox systems and the research on the electrochemical behavior of these compounds has been actively pursued for many decades starting from the beginning of the twentieth century [1]. The electrochemical behavior associated with electron-proton transfer equilibrium and kinetics provides information on molecular structure [2-5] and the environment of the basic process [6-9]. To find out their mode of action, evaluation of reaction mechanisms and determination of physicochemical parameters, studies on the reduction of these molecules under different conditions were carried out [6-17]. Besides chemical aspects, quinones play important roles in the biochemistry of living cells [18-35]. Anthracyclines, a class of anthraquinones are used as medicine in several types of human cancer [36-63] where it has been observed that their biological activities are associated with their redox behavior [18-63]. Thus it becomes necessary to understand the environmental factors which regulate the potentials and reaction pathways of various species that appear in the quinone-hydroquinone systems in biology. Pulse radiolysis techniques [64-68], electron spin resonance $[64,65,69]$, and electrochemical methods like polarography, cyclic voltammetry, square wave voltammetry and so forth, have been used to investigate redox behavior of different quinone systems [70-109].

In aqueous buffer, at acidic, neutral, and alkaline $\mathrm{pH}$ anthracyclines, anthraquinones, and other para-quinones undergo reversible two-electron reduction in which the reduction potential varies with $\mathrm{pH}$ in a straightforward Nernstian manner. At acidic $\mathrm{pH}$, the reduction is a single step two-electron two-proton process while in alkaline $\mathrm{pH}$ the reduction does not involve proton and is only a case of two-electron reduction [77, 86-89]. At neutral $\mathrm{pH}$, the reduction is either one proton two-electron or only twoelectron without the participation of proton [77, 86-89].

In neutral aprotic media, the quinones $(\mathrm{Q})$ undergo two successive one-electron reduction steps to produce semiquinone $\left(\mathrm{Q}^{\bullet-}\right)$ and quinone dianion $\left(\mathrm{Q}^{2-}\right)$ generating 
two separate cathodic waves in which the first step is completely reversible and the second step is quasireversible at customary scan rates [110-122]. Electron spin resonance has been used to demonstrate the presence of quinone radicals as intermediates in the redox processes $[64,65,69]$. The potentials of these redox systems depend on the stability of the reduced species. Polarity of the solvents, nature of the supporting electrolyte, intra or intermolecular hydrogen bonding, presence of acidic or basic additives, ion pairing and protonation-deprotonation equilibrium play a crucial role in stabilizing reduced forms of quinones. Cation of the supporting electrolyte forms an ion pair with semiquinone and quinone dianion while acidic additives form hydrogen bond with the reduced species that stabilizes semiquinone and dianion. Many studies have been devoted to the ion pair formation processes between electrochemically reduced quinones and cationic species [7, 123]. The shift of polarographic half-wave potentials provide useful information to determine the association constant and stoichiometry of the ion pair formed in the vicinity of the electrode. In hydroxy quinones, the presence of the hydroxy functionality seems to be related to the biological activity of this kind of compound [124-128] and the position of this functional group can alter the typical redox behavior of the quinonoid moiety [129131] owing to the formation of intramolecular hydrogen bonds in the reduced species. This is relevant, considering that most of the biological activity of quinonoid systems is related to their capacity to carry out free radical generation via redox reactions. Previous results for hydroxy substituted anthraquinones and naphthoquinones have been compared with that of 9,10-anthraquinone and 1,4-naphthoquinone to find out effect of hydroxy substitution on the geometry and electronic structure of anthraquinone and naphthoquinone.

This paper covers an area of research on electrochemical behavior of quinones from chemical to the biochemical domain. The aim of this paper is to provide an indepth understanding on specific aspects of the reduction of quinones at different electrodes using different solvents, electrolytes, experimental conditions by using different electrochemical methods.

\section{Electrochemical Aspects of Quinones}

2.1. Biological Aspects of Quinones. Anthracycline drugs, a class of anthraquinones used as anticancer drugs [36] are effective against acute leukemia, malignant lymphomas and also active in solid tumours, particularly in case of breast cancer [36-45]. To decrease toxicity and increase therapeutic action new analogues and derivatives of these drugs are being formulated and tried clinically [36-38]. The cardiotoxicity [45-47] and chromosome damaging property [48] of the anthracyclines limit their use in cancer chemotherapy. Both cardiotoxicity and chromosomal damages are associated with several electron transfer processes involving the respiratory chain generating $\mathrm{H}_{2} \mathrm{O}_{2} / \mathrm{O}_{2}{ }^{--} / \mathrm{OH}^{-}$. Participating in radical reactions anthracycline drugs initiate oxidative phosphorylation, complexation of phospholipid, and peroxidation of several lipids [49-54]. Several studies have shown that both therapeutic efficiency and toxicity of such drugs have good correlation with redox properties [55-58]. The quinone moiety present in these drugs after one electron reduction forms semiquinone that plays a major role in determining toxicities of these drugs in cellular systems [59, 60]. Other quinones such as ubiquinones, are well-known important functional moiety in various biological systems acting as an electron-proton carrier in respiratory assemblies and in photosynthetic electron flow systems [18]. These paraquinones are reduced to semiquinones by mitochondrial NADH dehydrogenase [23-31, 40, 62, 63]. The reoxidation of semiquinone leads to the production of $\mathrm{O}_{2}{ }^{-}$from where hydrogen peroxide and hydroxyl radical $\left(\mathrm{HO}^{\bullet}\right)$ arise and these active species are reported to degrade DNA by abstracting hydrogen from the deoxyribose residues [23, 24, $30-35,40,62,63]$.

\subsection{Electrochemical Reduction in Aqueous Media}

\subsubsection{Electrochemical Reduction in Buffered Aqueous Media.} In buffered aqueous media (including mixtures with ethanol, methanol, etc.) quinone-hydroquinone couples provide familiar single step two-electron redox systems in which potentiometric or polarographic potentials vary with $\mathrm{pH}$ in a straightforward Nernstian manner [132]. This behavior was conveniently summarized in E-pH diagrams (Pourbaix diagrams), showing regions of existence of various redox and protonated species and their respective $\mathrm{pK}_{\mathrm{a}}$ values $[2,3$, $70,71,133]$. It was shown that in aqueous buffer, at acidic, neutral and alkaline $\mathrm{pH}$ anthracyclines, anthraquinones, and other para-quinones are reduced by two electrons generating one reversible wave in cyclic voltammetry. At acidic $\mathrm{pH}$ the reduction is a single step two-electron two-proton process (Scheme 1) [72-77] and in alkaline $\mathrm{pH}$ the reduction does not involve proton and is only a case of two-electron reduction (Scheme 2) [77, 86-89]. At neutral pH, the reduction is either by one proton two electrons or only two electrons without the participation of proton [77, 86-89].

The reduction of para-benzoquinone in aqueous solution was studied by different workers [99, 100] and the mechanism of such reduction in aqueous solution was summarized as follows:

$$
\begin{gathered}
\mathrm{Q}+\mathrm{e} \leftrightharpoons \mathrm{Q}^{\bullet-} \\
\mathrm{Q}^{\bullet-}+\mathrm{H}^{+} \leftrightharpoons \mathrm{QH}^{\bullet} \\
\mathrm{QH}^{\bullet}+\mathrm{e} \leftrightharpoons \mathrm{QH}^{-} \\
\mathrm{QH}^{-}+\mathrm{H}^{+} \leftrightharpoons \mathrm{QH}_{2}
\end{gathered}
$$

The sequence of the reactions is described as two rounds of electron-transfer coupled with proton acceptance (chemical reaction) that is ECEC or EHEH mechanism. In absence of protons the para-benzoquinone is reduced to its dianion, $\mathrm{Q}^{2-}$. When the acidity of the medium is high, the two protonation steps can be so fast that the whole reaction affords directly hydroquinone $\mathrm{QH}_{2}$ as product

$$
\mathrm{Q}+2 \mathrm{H}^{+}+2 \mathrm{e} \leftrightharpoons \mathrm{QH}_{2}
$$




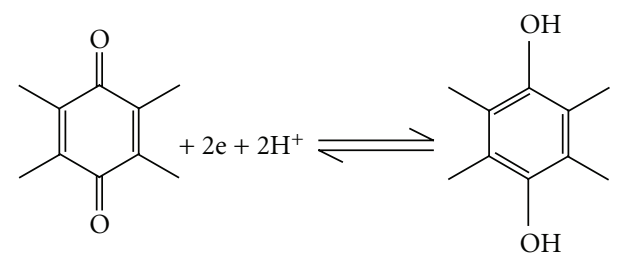

Scheme 1: Two-electron two-proton reduction of quinone in aqueous buffer.

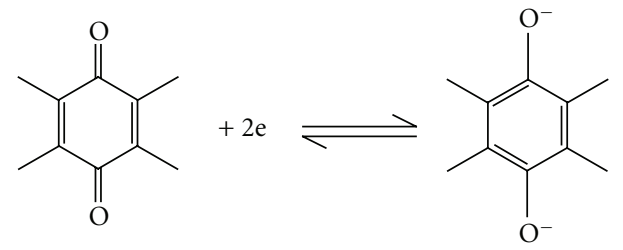

Scheme 2: Two-electron reduction of quinone in aqueous buffer.

This reaction forms the basis of what is known as a "quinone/hydroquinone electrode" used in $\mathrm{pH}$ measurements.

At acidic and neutral $\mathrm{pH}$ in addition to a reversible reduction peak corresponding to two-electron reduction an irreversible reduction peak has been observed for anthracyclines and hydroxy-9,10-anthraquinones. Several studies on the electrochemical behavior of adriamycin (doxorubicin hydrochloride) and daunorubicin (daunomycin) (Scheme 3) by different researchers have been extensively carried out over a few decades [72-76, 78-86]. Rao et al. [72] and Molinier-Jumel et al. [73] have discussed the mechanism involved in the reduction of anthracyclines at mercury electrodes and attempted to correlate the observed behavior with their therapeutic actions. In both studies two reduction peaks are observed; one approximately at $-600 \mathrm{mV}$ versus saturated calomel electrode that is completely reversible and involves two-electron reduction of the quinone to hydroquinone while the second reduction is irreversible and occurs at more negative potential assigned to the irreversible reduction of the side chain carbonyl adjacent to the anthraquinone nucleus of adriamycin.

At carbon paste electrode, at $\mathrm{pH} 4.5$, adriamycin shows two sets of waves one at a positive $(+500 \mathrm{mV})$ and another at a negative $(\sim-600 \mathrm{mV})$ potential [74]. The oxidation peak at $+500 \mathrm{mV}$ is reversible and involves the oxidation of the hydroquinone group of the dihydroxy-9,10-anthraquinone moiety. The reduction peak at negative potential $(\sim-600 \mathrm{mV})$ was similar to the previously reported reduction of anthracycline quinones to hydroquinone $[72,73]$. This reduction peak at negative potential shifted anodically by approximately $60 \mathrm{mV} / \mathrm{pH}$ unit as the $\mathrm{pH}$ was decreased and appeared to be reversible in more acidic condition ( $\mathrm{pH} 2.3$ ). This suggests that at acidic $\mathrm{pH}$ adriamycin is reduced by the mechanism of two electrons and two protons. Thus at carbon

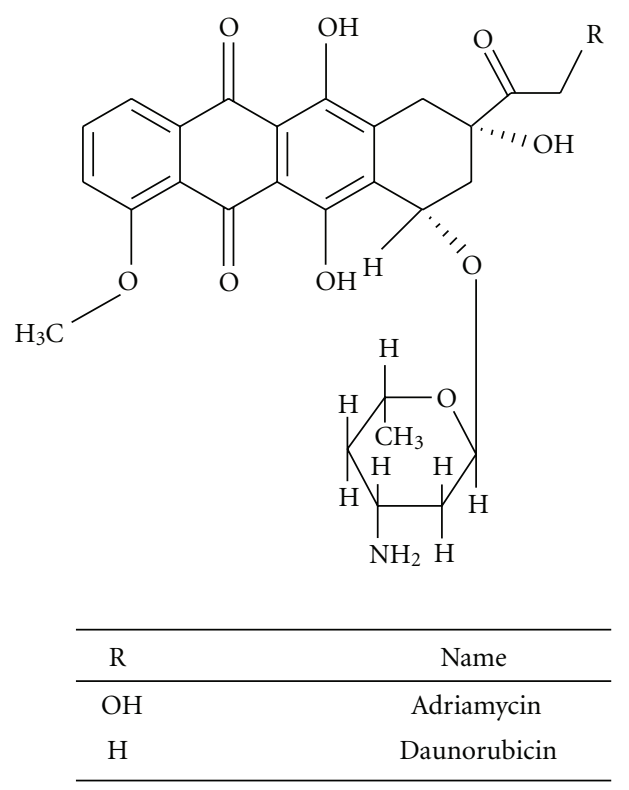

Scheme 3: Structure of adriamycin and daunorubicin.

paste electrode at $\mathrm{pH} 4.5$ two distinct sets of waves were observed for adriamycin which corresponds to two types of redox processes as mentioned above. However, at more acidic and neutral $\mathrm{pH}$ only one peak was observed which indicates that under such conditions both redox processes mentioned above take place at nearly the same potential.

The electrochemical reduction at carbon paste electrode is adsorption controlled. In order to establish the adsorption Chaney and Baldwin [75] carried out differential pulse voltammetry of extraordinarily low concentration $\left(1.0 \times 10^{-8} \mathrm{M}\right)$ of adriamycin at $\mathrm{pH} 4.5$ and observed a well-defined peak clearly indicating that electrochemical reduction in the carbon paste electrode is adsorption controlled. The peak at $+0.5 \mathrm{~V}$ in square wave voltammetry was successfully utilized for the quantitative determination of adriamycin in unknown samples.

Kano et al. [76] studied the electrochemical properties of adriamycin and one of its simple analogue quinizarin $(1,4-$ dihydroxy-9,10-anthraquinone) (Scheme 4) at $\mathrm{pH} 4.54$ by cyclic a.c. and d.c. voltammetry using a hanging mercury drop electrode. It has been established that under such experimental conditions the electrochemical reaction is purely adsorption controlled with diffusion being negligible. The cyclic d.c. voltammetry shows two reduction peaks, one at $-450 \mathrm{mV}$ and another at $-1130 \mathrm{mV}$. The first reduction is completely reversible while the other is irreversible. The $\mathrm{pH}$ dependence of the first peak is $60 \mathrm{mV} / \mathrm{pH}$ unit in the $\mathrm{pH}$ range of 2 to 6 indicating a two-electron two-proton redox process. The nature of the a.c. and d.c. voltammogram is almost similar. The peak potential of the second reduction shifts by about $50 \mathrm{mV}$ for a 10 -fold increase in scan rate in the range 10 to $500 \mathrm{mV} / \mathrm{s}$. Further, they showed peak current grows parabolically with scan rate and the temperature coefficient of this peak current is $6.3 \%$ in the temperature range $10^{\circ} \mathrm{C}$ to $40^{\circ} \mathrm{C}$. These indicate that the reduction 
<smiles>[Y]c1ccc2c(c1[Y])C(=O)c1c([R])cc([Y])c([Y])c1C2=O</smiles>

\begin{tabular}{cccccc}
\hline $\mathrm{R}^{1}$ & $\mathrm{R}^{2}$ & $\mathrm{R}^{3}$ & $\mathrm{R}^{4}$ & $\mathrm{R}^{5}$ & Name \\
\hline $\mathrm{OH}$ & $\mathrm{H}$ & $\mathrm{OH}$ & $\mathrm{H}$ & $\mathrm{H}$ & Quinizarin \\
$\mathrm{OH}$ & $\mathrm{SO}_{3}{ }^{-}$ & $\mathrm{OH}$ & $\mathrm{H}$ & $\mathrm{H}$ & Quinizarin-2-sulphonate \\
$\mathrm{SO}_{3}{ }^{-}$ & $\mathrm{H}$ & $\mathrm{H}$ & $\mathrm{H}$ & $\mathrm{H}$ & Anthraquinone-1-sulphonate \\
$\mathrm{H}$ & $\mathrm{SO}_{3}{ }^{-}$ & $\mathrm{H}$ & $\mathrm{H}$ & $\mathrm{H}$ & Anthraquinone-2-sulphonate \\
$\mathrm{SO}_{3}{ }^{-}$ & $\mathrm{H}$ & $\mathrm{H}$ & $\mathrm{SO}_{3}{ }^{-}$ & $\mathrm{H}$ & Anthraquinone-1,5-disulphonate \\
$\mathrm{H}$ & $\mathrm{SO}_{3}{ }^{-}$ & $\mathrm{H}$ & $\mathrm{H}$ & $\mathrm{SO}_{3}{ }^{-}$ & Anthraquinone-2,6-disulphonate \\
$\mathrm{COOH}$ & $\mathrm{H}$ & $\mathrm{H}$ & $\mathrm{H}$ & $\mathrm{H}$ & Anthraquinone-1-carboxylic acid \\
\hline
\end{tabular}

Scheme 4: Structures of different anthraquinones.

is kinetic or catalytic in character. Similar second reduction peak was observed in quinizarin (1,4-dihydroxy-9,10anthraquinone) [76] and sodium quinizarin-2-sulphonate (sodium 1,4-dihydroxy-9,10-anthraquinone-2-sulphonate) [77] (Scheme 4), but such reduction peak was not observed in case of pure anthraquinone. From these observations, it was suggested that the presence of two adjacent hydroquinone moieties is essential for such a reduction peak and was proposed to be due to hydrogen evolution. Addition of dimethylformamide or alkali to the reaction media makes such irreversible peak very small or it completely vanishes [77]. Since DMF has proton abstracting power [134-137] therefore, it reduces or vanishes hydrogen evolution peak [76]. Kano et al. clearly showed that $20 \%$ DMF completely vanishes the hydrogen evolution peak of adriamycin and quinizarin [76]. This supports the fact that the reduction peak is actually due to hydrogen evolution current, which is catalyzed by two hydroxy groups adjacent to benzene rings containing the quinone [76, 77]. Rao et al. [72] described the second reduction as an irreversible reduction of the side chain carbonyl adjacent to the anthraquinone nucleus on the basis of its similarity to the reduction processes of acetophenone and $1^{\prime}$-acetophenone. However, the side chain carbonyl of adriamycin is aliphatic and is not conjugated to the aromatic ring like the carbonyl of acetophenone. Therefore, it is difficult to reduce such aliphatic carbonyl group of adriamycin. In general, the reduction of aliphatic ketone was not observed in the usual buffer solution [73]. Further, Rao's assignment cannot explain the second irreversible reduction peak for quinizarin and quinizarin-2-sulphonate which do not possess the side chain carbonyl group [76, 77].

The electrochemical behavior of doxorubicin hydrochloride (adriamycin) using cyclic and square wave voltammetry in acetate buffer at different $\mathrm{pH}$ values using hanging mercury drop electrode was studied by Hahn and Lee [80]. They established that doxorubicin hydrochloride is reduced by two electrons and two protons at hanging mercury drop electrode at acidic $\mathrm{pH}$ and that the reduction is quasi-reversible. The peak current is directly proportional to the concentration of doxorubicin and using this linear relation concentrations of doxorubicin in the unknown sample has been determined with very high precision [80]. El-Hady et al. [81] studied the electrochemical behavior of $\mathrm{Cu}$ (II) complex of adriblastina (adriamycin or doxorubicin hydrochloride) and its interaction with DNA by square wave voltammetry. They were able to show that the electrochemical reduction of such a complex is reversible but irreversibility increases with increase of $\mathrm{pH}$.

Zhang et al. [82] analyzed the electrochemical behavior of adriamycin at carbon paste electrode in presence of cationic surfactant cetyltrimethylammonium bromide $(\mathrm{CTAB})$. Adriamycin adsorbed strongly at the electrode surface assisted by CTAB thereby affecting the peak current and reduction potentials. In presence of CTAB the reduction at $-0.500 \mathrm{~V}$ was seen to be irreversible and was used to determine the concentration of adriamycin in practical determinations [82]. Hu and $\mathrm{Li}$ [83] studied electrochemical property of adriamycin using $\mathrm{CH}_{3} \mathrm{COOH}-$ $\mathrm{CH}_{3} \mathrm{COONa}$ as supporting electrolyte at glassy carbon (GC) electrode and $\mathrm{Ni}$ ion-implanted glassy carbon electrode $(\mathrm{Ni} / \mathrm{GC})$ by linear sweep voltammetry. They performed experiments with different electrolytes like $0.05 \mathrm{M} \mathrm{H}_{2} \mathrm{SO}_{4}$, $0.1 \mathrm{M} \mathrm{HCl}, 0.1 \mathrm{M} \mathrm{CH} \mathrm{CH}_{3} \mathrm{COOH}-\mathrm{CH}_{3} \mathrm{COONa}, 0.1 \mathrm{M} \mathrm{KCl}$, $0.1 \mathrm{M} \mathrm{NH}_{3}-\mathrm{NH}_{4} \mathrm{Cl}, 0.1 \mathrm{M} \mathrm{NaOH}$ and found that with $0.1 \mathrm{M}$ $\mathrm{CH}_{3} \mathrm{COOH}-\mathrm{CH}_{3} \mathrm{COONa}$ peak shape and size was good and sensitivity was reasonably high. It was found that as the $\mathrm{pH}$ was increased the peak current also increased tending to stabilize to a certain value for $\mathrm{pH}$ in the range 3.725; for all $\mathrm{pH}$ beyond 5.0 the peak current decreased. Due to this reason, $0.1 \mathrm{M} \mathrm{CH} \mathrm{CH}_{3} \mathrm{COOH}-\mathrm{CH}_{3} \mathrm{COONa}(\mathrm{pH} 4.62$ ) was chosen for this experiment and the concentration of adriamycin was determined quantitatively. They established that determination of adriamycin at low concentration is 


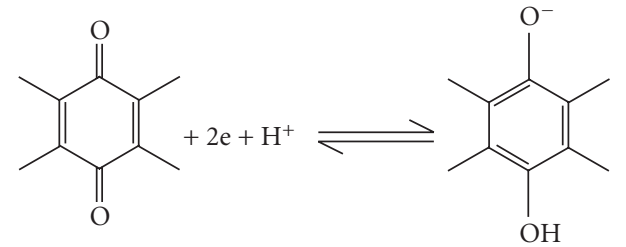

Scheme 5: Two-electron one-proton reduction of quinone in aqueous buffer.

more effective using a Ni/GC than GC electrode illustrating higher catalytic activity of Ni/GC than the glassy carbon (GC) electrode for the reduction of adriamycin. Using this method adriamycin was determined in urine samples of patients undergoing active adriamycin chemotherapy. In the same study it was found that the cathodic peak current has a linear relationship with the square root of the scan rate indicating that the reaction is diffusion controlled and that there is no adsorption at the electrode surface.

Electrochemical behavior of adsorbed daunomycin on hanging mercury drop electrode (HMDE) was studied in aqueous buffer at $\mathrm{pH} 9.18$, and it was observed that the compound undergoes two-electron reduction following ECE pathway [84]. The result corroborates previous results [85].

Several researches $[77,86-109,137,138]$ have been carried out on different derivatives of anthraquinone and dihydroxy-9, 10-anthraquinones to see whether they mimic basic electrochemical properties of anthracycline drugs. As the solubility of anthraquinone or dihydroxy-9,10-anthraquinones is small therefore in most cases their soluble derivatives were used. Gill and Stonehill [86] and Furman and Stone [87] studied the electrochemical properties of anthraquinone-2-sulphonate at limited $\mathrm{pH}$ range in detail. They showed that it produced a well-defined polarographic wave in basic media. Their results were concordant with two-electron one-proton reduction to produce singly deprotonated dihydroxy-anthracene (Scheme 5). The unusual wave slope in polarography indicates adsorption process at the electrode. Guin et al. [88] carried out a chronocoulometry experiment on sodium 1,4-dihydroxy-9,10anthraquinone-2-sulphonate at acidic, neutral, and alkaline $\mathrm{pH}$ and reported that the quinone molecule undergoes two-electron reduction at any $\mathrm{pH}$. Anson and Epstein [89] noticed that cyclic voltammetry of anthraquinone-2sulphonate showed a sharp reduction peak which was due to adsorption of the molecule at the mercury electrode. Chronocoulometry was used to determine number of electrons involved in such reduction. The authors showed that in alkaline media the anthraquinone is reduced by two electrons. For other anthraquinone sulphonate molecules like anthraquinone-1-sulphonate, anthraquinone-1,5-disulphonate, anthraquinone-2,6-disulphonate, and so forth, (Scheme 4) adsorption at different working electrodes were seen by different workers $[64,90-106]$. He et al. [100] had shown that along with a reversible adsorption peak at $0.0 \mathrm{~V}$ there was a quasireversible diffusion peak at $-0.2 \mathrm{~V}$ in cyclic voltammetry experiment of anthraquinone-2- sulphonate. Another analogue anthraquinone-2-carboxylic acid was seen to adsorb at a gold electrode surface via selfassembly process $[107,108]$. Anthraquinone-2-sulphonate, anthraquinone-1,5-disulphonate, and anthraquinone-2,6disulphonate can be reduced by two electrons and two protons at acidic $\mathrm{pH}$. The two electrons and two protons reduction at acidic $\mathrm{pH}$ was also found for quinizarin [76] and sodium quinizarin-2-sulphonate [77]. In almost all the experiments two electrons two-proton reduction at acidic $\mathrm{pH}$ for anthracyclines and other anthraquinone molecules was confirmed by linear relationship of cathodic peak potential, $E_{\mathrm{pc}}$ versus $\mathrm{pH}$ with a slope of $\sim 60.00 \mathrm{mV} / \mathrm{pH}$. Controlled potential coulometry experiments were done to determine the number of electrons involved in the reduction of quinone to dihydroxy anthraquinone or semiquinone or the quinone dianion $[77,88,100]$. In controlled-potential coulometry the total number of coulombs consumed in electrolysis is used to determine the amount of substance electrolyzed. In aqueous buffer, the formal reduction potential of quinizarin-2-sulphonate varies with $\mathrm{pH}$ with values of $-420 \mathrm{mV},-470 \mathrm{mV}$, and $-485 \mathrm{mV}$ at $\mathrm{pH} 5.0,7.0$, and 9.0 respectively. At all these three $\mathrm{pH}$ that is acidic, neutral and alkaline $10^{-6}(\mathrm{M})$ quinizarin-2-sulphonate solutions were electrolyzed against constant potential of $-400 \mathrm{mV}$ for a long time and the number of coulombs was plotted against time. It was observed whatever is the $\mathrm{pH}$ of the solution, two electrons reduce quinizarin-2-sulphonate [88]. For anthraquinone-1,5-disulphonate, anthraquinone-2,6disulphonate and anthraquinone-2-sulphonate the number of electrons involved in the reduction was observed to be $1.79 \pm 0.01,1.93 \pm 0.02$ and $1.91 \pm 0.01$ [100]. The authors suggested that an early cut off of the chronocoulometry experiment or inaccurate background correction were the possible reasons for lowering of the number of electrons from the expected value of 2 .

For an ideal reversible adsorption peak the number of electrons involved in the reduction was also evaluated from the following relation $[100,109]$ :

$$
\left|E_{\mathrm{pc}}-\frac{E_{\mathrm{pc}}}{2}\right|=\frac{90.6}{n}
$$

$E_{\mathrm{pc}}$ is the cathodic peak potential while $E_{\mathrm{pc}} / 2$ is potential at half width of the cathodic peak. $n$ is the number of electrons involved in the process. Anthraquinone-2,6disulphonate undergoes adsorption controlled reversible reduction and the width $\left(\left|E_{\mathrm{pc}}-E_{\mathrm{pc}} / 2\right|\right)$ was observed to be 48 for reduction peak and 45.6 for the oxidation peak. Considering these values the authors suggested that two electrons are involved in the redox couple for the adsorbates, just as for the dissolved species [100].

The electrochemical reduction of sodium 1,4-dihydroxy9,10-anthraquinone-2-sulphonate at glassy carbon electrode surface in both aqueous and dimethylformamide media was found to be diffusion controlled [77]. Like anthracyclines, sodium 1,4-dihydroxy-9,10-anthraquinone2-sulphonate was seen to generate two reduction peaks in which the first reduction is that of the reduction of the quinone while the second reduction peak is the hydrogen evolution peak at acidic $\mathrm{pH}$. The first peak current $\left(I_{\mathrm{pc}}\right)$ 
has linear relationship with square root of scan rate and it passes through the origin suggesting a diffusion controlled electrochemical reaction with no adsorption on the electrode surface.

Koyama et al. [138] studied the electrochemical behavior of ten azo-naphthoquinone compounds to correlate their redox behavior on inhibitory effects on Epstein-Bar virus activation. They showed that at $\mathrm{pH} 7.2$ the naphthoquinones were reduced reversibly by two electrons and that the electrode process was mainly diffusion-controlled with minor contributions due to adsorption at the electrode surface.

Studies on the reduction of anthraquinone sulphonates were extended from acidic to alkaline $\mathrm{pH}$ by Guin et al. [77] and He et al. [100]. $\mathrm{pK}_{1}$ and $\mathrm{pK}_{2}$ of the newly formed phenolic $-\mathrm{OH}$ groups at the 9 and 10 positions of the anthraquinone are expected to be approximately 7.35 and 10.3, respectively [100]. Therefore, reduced forms of anthraquinone sulphonate molecules near $\mathrm{pH} 7.0$ exist as a monoanion and so anthraquinone at $\mathrm{pH}$ close to 7.0 can be reduced by two electrons and one proton [100]. At high $\mathrm{pH}$ the reduced form exists as a quinone dianion specie and anthraquinones are reduced by two electrons only $[77,133]$. In case of dihydroxy-9,10-anthraquinone like sodium 1,4-dihydroxy-9,10-anthraquinone-2-sulphonate, [77] for $\mathrm{pH}>\mathrm{pK}_{\mathrm{a}}$ the newly formed phenolic -OH groups at 9 and 10 positions of the molecule experience strong hydrogen bond between anionic quinone oxygens and phenolic - $\mathrm{OH}$ of 1- and 4-positions, respectively, resulting in an almost steady value of reduction potential. After $\mathrm{pH}$ 9.0, the reduction potential further drops with $\mathrm{pH}$ and is due to deprotonation of phenolic $-\mathrm{OH}$ at position 1 $(\mathrm{pK}=9.2[77])$ which disrupts the stabilizing influence of hydrogen bonding with a simultaneous onset of ionic repulsion between two negatively charged oxygen atoms at 1 and 9, respectively. Thus the product is less stable and results in a decrease in formal potential.

2.2.2. Electrochemical Reduction in Unbuffered Aqueous Media. There are few reports on the electrochemical behavior of quinones in unbuffered aqueous media [2, 3, 139-148]. When the proton concentration nearly equals concentration of the quinone results are consistent with that observed in aqueous buffered media but sometimes explanations are different. In most cases the reduction is two protons two electrons or two electrons only. Shim et al. [139, 140] interpreted this as a case of one-electron reduction that was ruled out by other workers [141-143]. Depending upon the $\mathrm{pK}_{\mathrm{a}}$ of hydroquinone the species $\mathrm{QH}_{2}, \mathrm{QH}^{-}$, and $\mathrm{Q}^{2-}$ are formed. The mono- and dianions are stabilized by hydrogen bonding involving solvent water molecules. Hence, depending upon the $\mathrm{pH}$ of the media the nature of reduction varies.

March et al. have extended their study [149] by using 5-hydroxy-3-hexanedithiol-1,4-naphthoquinone which was self-assembled on gold electrode to obtain an electroactive monolayer. This was subjected to cyclic voltammetry experiments in phosphate buffer-saline medium at $\mathrm{pH}$ 7.4. A quasi-reversible signal was observed with cathodic and anodic peaks at $-0.45 \mathrm{~V}$ and $-0.36 \mathrm{~V}$, respectively. A kinetic analysis of the redox reactions involving both electron and proton transfer has revealed an unusual behavior of this molecule due to the presence of the hydroxyl function in the vicinity of the quinone group. The apparent kinetic rate constant and the anodic electron transfer coefficient of this reaction is seen to depend on $\mathrm{pH}$. In acid medium, a classical $2 \mathrm{e}^{-} / 2 \mathrm{H}^{+}$mechanism was obtained. In basic medium $(\mathrm{pH}>7)$, strong intramolecular hydrogen-bonding interactions between the quinone and the hydroxyl function have a strong influence on redox kinetics. By studying the factors influencing the kinetics of the redox reactions, it has been found that hydrogen-bonding interactions have a critical role in the rate limiting step.

\subsection{Electrochemical Reduction in Nonaqueous Media. In non-} aqueous media, the reductions of quinones (Q) take place by two successive one-electron reduction steps generating two separate cathodic waves in which the first step is completely reversible and the second step is quasi-reversible at customary scan rates [110-122]. The peak currents of first and second reduction waves are proportional to square root of the scan rate, indicating a diffusion controlled process $[77,122,133,150-153]$. The first step corresponds to the formation of a semiquinone radical $\mathrm{Q}^{\bullet-}$ while the second step corresponds to the formation of quinone dianion, $\mathrm{Q}^{2-}$. Semiquinone radicals are short lived and readily undergo disproportionation $[2,3,154]$ generating a quinone and its corresponding dianion. Polarity of solvents, ion-pair formation, nature of supporting electrolyte, protonationdeprotonation equilibrium, intra- and intermolecular hydrogen bonding and addition of different acidic species or addition of water play important roles in determining the two formal reduction potentials.

2.3.1. Influence of Hydrogen Bonding, Acidic, and Basic Additives on Reduction. The semiquinone radical and quinone dianion formed are sometimes stabilized by strong hydrogen bonding between the anionic quinone oxygen and the phenolic $-\mathrm{OH}$ protons present at $\beta$-positions with respect to quinone oxygen. Ashnagar et al. [151] carried out the electrochemical reduction of 9,10-anthraquinone, 1,4naphthoquinone, and their analogues. It was established that introduction of hydroxy groups at 5- and 8-positions of the 1,4-naphthoquinone nucleus and 1-, 4-, 5- and 8 -positions of the 9,10-anthraquinone nucleus increases their reduction potentials. Presence of 1-hydroxy and 1,4dihydroxy substituents raises the first formal reduction potential relative to 9,10 -anthraquinone by $199 \mathrm{mV}$ and $273 \mathrm{mV}$, respectively. In case of naphthoquinones similar increments of the two potentials were observed. Insertion of methoxy groups at the positions mentioned above for both types of quinones do not show any change as observed in case of the hydroxy substituents. When only one $-\mathrm{OH}$ group is present at any of the positions mentioned above then only the semiquinone radical is stabilized leading to an increase in the first reduction potential. However, when two $-\mathrm{OH}$ groups are present adjacent to quinone oxygens then both the semiquinone radical as well as the quinone dianion gets stabilized through hydrogen bond formation leading to an increase in both reduction potentials $[77,110]$. 
Electrochemical reduction of 2-hydroxy-1,4-naphthoquinone and perezone (2-(1,5-dimethyl-4-hexenyl)-3-hydroxy-5-methyl-1,4-benzoquinone) (Scheme 6) in acetonitrile was studied using cyclic voltammetry and chronoamperometry and the mechanism of such reduction was proposed $[131,155]$. For these molecules there is an initial electron transfer step followed by self-protonation (shown below). The products of reduction are the protonated semiquinone and a deprotonated original quinone. Both interact with an electron forming species shown as products in (3c) and (3f), respectively. Product of (3c) later interacts with another quinone molecule resulting in $\mathrm{H}_{2} \mathrm{Q}-\mathrm{OH}$ and forming another deprotonated original quinone:

$$
\begin{gathered}
\mathrm{Q}-\mathrm{OH}+\mathrm{e} \rightleftharpoons(\mathrm{Q}-\mathrm{OH})^{\bullet-} \\
(\mathrm{Q}-\mathrm{OH})^{\bullet-}+\mathrm{Q}-\mathrm{OH} \longrightarrow(\mathrm{HQ}-\mathrm{OH})^{\bullet}+\mathrm{Q}^{-} \mathrm{O}^{-} \\
(\mathrm{HQ}-\mathrm{OH})^{\bullet}+\mathrm{e} \rightleftharpoons(\mathrm{HQ}-\mathrm{OH})^{-} \\
(\mathrm{HQ}-\mathrm{OH})^{-}+\mathrm{Q}-\mathrm{OH} \longrightarrow \mathrm{H}_{2} \mathrm{Q}-\mathrm{OH}+\mathrm{Q}^{-} \mathrm{O}^{-} \\
3 \mathrm{Q}-\mathrm{OH}+2 \mathrm{e} \longrightarrow \mathrm{H}_{2} \mathrm{Q}-\mathrm{OH}+2 \mathrm{Q}^{-} \mathrm{O}^{-} \\
\mathrm{Q}^{-} \mathrm{O}^{-}+\mathrm{e} \rightleftharpoons \mathrm{Q}-\mathrm{O}^{\bullet}=
\end{gathered}
$$

In an actual experiment reactions (3a) to (3d) summarized as (3e) takes place in a single-step two-electron reduction while the reaction shown by (3f) is a separate case of reduction that occurs on the in situ formed anion of the original quinone following cases of deprotonation (steps (3b) and (3d) as shown above. It could therefore be concluded from the above study that the first reduction wave corresponds to the overall reaction (3e) where two electrons reduce one of every three molecules of $\mathrm{QOH}$ producing the corresponding hydroquinone $\left(\mathrm{H}_{2} \mathrm{Q}-\mathrm{OH}\right)$ while the other two quinones two conjugated base species $\left(2 \mathrm{Q}^{-} \mathrm{O}^{-}\right)$. The second reduction wave corresponds to the one electron reduction of $\mathrm{Q}_{-} \mathrm{O}^{-}$to $\mathrm{Q}-\mathrm{O}^{\bullet}$. . However, there is some controversy with regard to the electrochemical reduction of the conjugate base formed from such hydroxy quinones [156-161].

The set of reactions (3a)-(3f) was assumed in some other study using compounds having such type of hydroxy groups [158, 162-168]. The radical dianions formed were detected by Electrochemical-Electron Spin Resonance coupled experiments (EV-ESR). Addition of tetrabutylammonium hydroxide increases ESR signal intensity and proves the radical nature of the species. In acetonitrile along with two reversible reduction waves like other quinones the compounds showed a third irreversible oxidation peak at positive potential. Frontana and coworkers suggested this third oxidation peak to be the oxidation of an intermediate formed during selfprotonation pathway [163].

González and coauthors [130] have worked with perezone in acetonitrile using linear sweep voltametry and single potential step chronoamperometry. The reduction of perezone involves a monoelectronic charge-transfer step, followed by a protonation step and homogeneous charge transfer due to disproportionation of the protonated intermediate. The mechanism for the homogeneous charge-transfer<smiles>O=CC=CC=O</smiles>

1,4-naphthoquinone<smiles>O=C1C=C(O)C(=O)c2ccccc21</smiles>

2-hydroxy-1,4-naphthoquinone<smiles>CCCCCCCC=CC(C)C</smiles>

Perezone

Scheme 6: Structures of naphthoquinones and perezone.

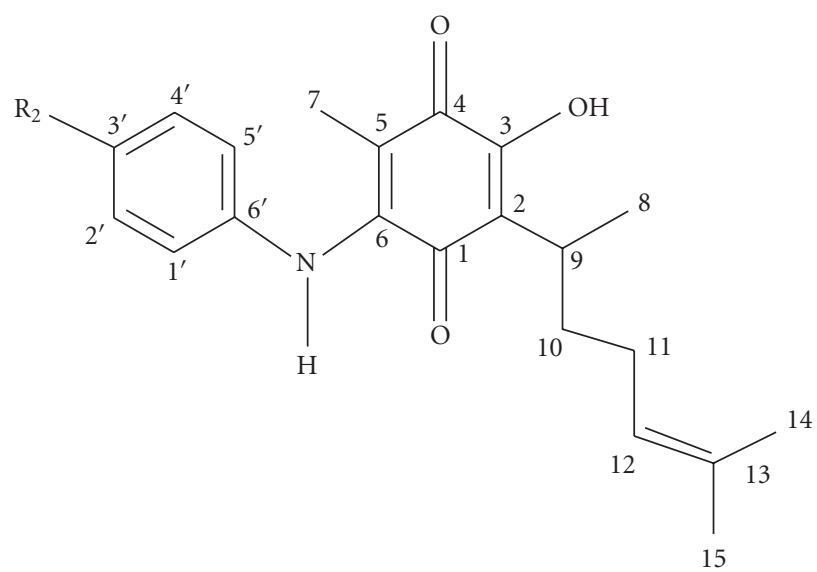

Anilinoperezones

Scheme 7: Structure of anilinoperezones, $\mathrm{R}_{2}=-\mathrm{OH},-\mathrm{OMe},-\mathrm{Me}$, $-\mathrm{Br}$, and $-\mathrm{CN}$.

step was found to be first order disproportionation from results of double potential step chronoamperometry experiments that were carried out in mildly acidic medium [130].

Electrochemical behavior of some $\mathrm{C}_{6}$ para-substituted anilinebenzoquinones (APZs) (Scheme 7) derived from perezone (Scheme 6) were analyzed in acetonitrile using cyclic voltammetry to find out the effect of substituents on quinone electronic properties by Aguilar-Martínez et al. [131]. The effect of hydrogen bonding between $\alpha$-hydroxy and quinone oxygen was determined in perezone derivatives by different substituting electron-donor and electronacceptor groups like $-\mathrm{OMe},-\mathrm{Me},-\mathrm{Br}$, and $-\mathrm{CN}$ and comparing the -OH (APZs) and-OMe (APZms) derivatives. The typical behavior of quinones with $\alpha$-phenolic protons, in an aprotic medium was not observed for APZs due to 
the presence of coupled, self-protonation reactions. The selfprotonation process gives rise to an initial wave, corresponding to the irreversible reduction of substituted quinone (HQ) to hydroquinone $\left(\mathrm{HQH}_{2}\right)$, and to a second electron transfer that is attributed to the reversible reduction of perezonate $\left(\mathrm{Q}^{\bullet-}\right)$ formed during the self-protonation process (discussed earlier) [155]. This reaction is favored by the acidity of the $\alpha$-OH located on the quinone ring. To control the coupled chemical reaction in one case methylation of the $-\mathrm{OH}$ group (APZms) was done while in another addition of a strong base, tetramethylammonium phenolate $\left(\mathrm{Me}_{4} \mathrm{~N}^{+} \mathrm{C}_{6} \mathrm{H}_{5} \mathrm{O}^{-}\right)$ completely deprotonated the APZs. In both cases there was a recovery of the reversible character of $\mathrm{Q} / \mathrm{Q}^{\bullet-}$ and $\mathrm{Q}^{\bullet-} / \mathrm{Q}^{2-}$.

Electrochemical property of anilinoperezones (2-(1, 5-dimethyl-4-hexenyl)-3-hydroxy-5-methyl-6-[4' -(R2-phenyl)amine]-1,4-benzoquinones, $\mathrm{PQOHs}$ ) (Scheme 7), in acetonitrile and in presence of different proton sources like benzoic acid, perchloric acid was studied and compared with its methylated derivatives (2-(1,5-dimethyl-4-hexenyl)3-methoxy-5-methyl-6-[4'-(R2-phenyl) amine]-1,4-benzoquinones, PQOMes) by Bautista-Martínez et al. [161]. To control self-protonation reactions mentioned above from occurring during electrochemical reduction of $\mathrm{PQOH}$, weak acids such as benzoic acid and a strong acid such as perchloric acid were used as acid additives while a weak base sodium benzoate and a strong base tetraethylammonium phenolate were used as basic additives. In aprotic medium, the PQOMe family exhibits electrochemical behavior typical of quinones in systems giving two reversible diffusion controlled waves with fast electron transfer characteristics in the absence of external and internal proton donors. This behavior indicated that the -NH group present in the structure of PQOMe does not show appreciable acidic properties in aprotic media. To verify the role of external acidic additives the reduction of PQOMe was carried out in the presence of buffer system benzoic acid-sodium benzoate. It was found that in presence of an acidic additive only one reduction wave appeared in more positive direction and the peak current was greater indicating a two-electron two-proton reduction corresponding to the reduction of quinone to dihydroquinone. This indicates that the semiquinone formed is stabilized by protonation. The mechanism was suggested as follows:

$$
\begin{gathered}
\mathrm{Q}+\mathrm{e} \rightleftharpoons \mathrm{Q}^{\bullet-} \\
\mathrm{Q}^{\bullet-}+\mathrm{HA} \rightleftharpoons \mathrm{A}^{-}+\mathrm{HQ}^{\bullet} \\
\mathrm{HQ}^{\bullet}+\mathrm{e} \rightleftharpoons \mathrm{HQ}^{-} \\
\mathrm{HQ}^{-}+\mathrm{HA} \rightleftharpoons \mathrm{H}_{2} \mathrm{Q}+\mathrm{A}^{-} \\
\mathrm{Q}+2 \mathrm{e}+2 \mathrm{HA} \rightleftharpoons \mathrm{H}_{2} \mathrm{Q}+2 \mathrm{~A}^{-}
\end{gathered}
$$

In case of PQOHs the first reduction peak is irreversible along with ill-defined shoulders in between the first and second reduction waves. Since the molecule contains internal proton donor centers therefore it undergoes reduction through self protonation reactions as reported in case of 2-hydroxy-1,4-naphthoquinone and perezone molecules
[155]. The ill-defined shoulders are associated with the reduction of quinone homoconjugated species (hydrogenbonded complexes) $[156,158,169]$. Like PQOMe in presence of acidic additives PQOHs also undergo two-electron twoproton reduction. In another work by Bautista-Martínez et al. [170] on electrochemical behavior of anilineperezones and their methylated derivatives in acetonitrile in presence of proton donor and withdrawing agent substituent effect in methylated compounds were correlated quantitatively.

Eggins and Chambers [171] also reported the effect of proton donors on the reduction of 1,4-benzoquinone in aprotic media. According to this report, when a weak acid such as benzoic acid was added, 1,4-benzoquinone undergoes an ECE process in which the first electron transfer follows a proton transfer while the second electron transfer happens apparently at the same potential. The cathodic peak potential $\left(E_{p}\right)$ depends on the concentration of the acid. In presence of a strong proton donor such as perchloric acid electrochemical behavior of 1,4-benzoquinone was altered significantly. The first reduction of 1,4-benzoquinone takes place at several tenths of a volt more positive than the original wave, and its peak current increased as the amount of acid increased. This new peak has been attributed to the prior protonation of quinone. However, the extent of peak shift $\left(\Delta E_{p}\right)$ depends not only on acidity of added proton sources but also on the basicity and structure of the quinones. It has been seen that in case of 1,4-benzoquinone (BQ) when the added acid source is stronger than corresponding dihydroquinone then prior protonation of the quinone $\left(\mathrm{BQH}^{+}\right)$ causes a new reduction peak at more positive potential than that of the first reduction wave of free quinone. When the added proton source is weaker than the dihydroquinone such as aliphatic alcohol then no proton transfer was found. The quinone dianion formed in the second reduction step is stabilized by hydrogen bond with such proton sources and change in the second reduction potential was significant while change in first reduction potential was very small. Organic Brønsted acids with medium strength act as proton sources on both steps of electron transfer. Therefore, both redox waves were significantly modified in presence of such acids. As most carboxylic acids, protonated alkylamines and phenol derivatives are regarded as Brønsted acids with medium strength, the redox behaviors of quinones in this study are understood on the basis of an ECE mechanism $[172,173]$. A new peak that appears at a more positive potential than the reduction peak due to reduction of free benzoquinone is clear and well developed. Stronger acids cause the potential of the new peak to be more positive. Thus, the difference between the potentials of the new and original reduction peaks, $\Delta E_{p}$, is sensitive to strength of the acid used. It has been seen that $\Delta E_{p}$ is maximum for tetramethyl benzoquinone and it was used to determine the concentration of various biologically active acids like pyruvic acid, maleic acid, and histamine quantitatively. From these it is clear that depending upon the concentration of proton in reaction media the conventional two-step one-electron reduction is significantly altered.

Gómez et al. [174] have studied the electrochemical behavior of 1,4-benzoquinone in presence of benzoic acid 


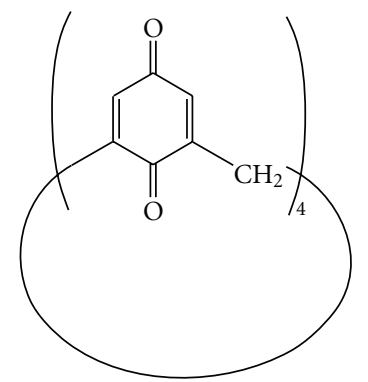

Scheme 8: Structure of calix-[4]-quinone.

and tetrabutylammonium hexafluorophosphate as supporting electrolyte in dimethylsulphoxide. They have observed that in absence of benzoic acid 1,4-benzoquinone generates two reversible reduction peaks Ic and IIc with their oxidation peaks Ia and IIa, respectively, corresponding to the formation of semiquinone $\mathrm{Q}^{\bullet-}$ and the dianion $\mathrm{Q}^{2-}$ (Figure 1). However, in presence of benzoic acid the waves IIc, IIa, and Ia disappear and a new cathodic wave IIIc and anodic wave IIIa develop at more positive potential (Figure 1). They have suggested this modification as a consequence of the protonation of the semiquinone $\mathrm{Q}^{\bullet-}$ and the rapid reduction of the protonated semiquinone $\mathrm{QH}^{\bullet}[110,131,159]$. Therefore, the signal IIIc represents an overall two-electron reduction mechanism, which can be considered as an ECE or a disproportionation process [176], and the wave IIIa corresponds to the oxidation of the protonated dianion $\mathrm{QH}^{-}$(Figure 1).

Calix-[4]-quinone (Scheme 8) consists of four parabenzoquinone units connected in parallel by four $-\mathrm{CH}_{2}$ groups present in between. Each para-benzoquinone unit undergoes reversible two one-electron reductions to form semiquinone and quinone dianion in rigorously dried acetonitrile solvent [175] like a simple para-benzoquinone molecule [2,3]. The authors [175] have shown that the four para-benzoquinone units are reduced consecutively in which the first two quinone units are reduced at less negative potentials while the reduction of other two units occur at more negative potentials (Figure 2). The difference in peak potentials between the second and third waves were significantly larger than those between the first and second as well as the third and fourth waves, indicating that the first two-electron transfers take place at the first and third para-benzoquinone units (Figure 2). The third electron transfer, however, occurs at the second parabenzoquinone unit, which is located between the two parabenzoquinone anion radicals, resulting in a large resistance to the incoming electron. This explains why the potential differences between the first and second waves, as well as the third and fourth waves, are smaller than that between the second and third waves. These quinone radical anions are reduced to quinone dianions and as dianions are more reactive, the reversibility of the last two waves is significantly reduced compared to that of first two waves. In presence of a strong acid like $\mathrm{HClO}_{4}$ the calix-[4]-quinone undergoes eight-proton eight-electron reduction. The electrochemical reduction of calix-[4]-quinone was also studied by other

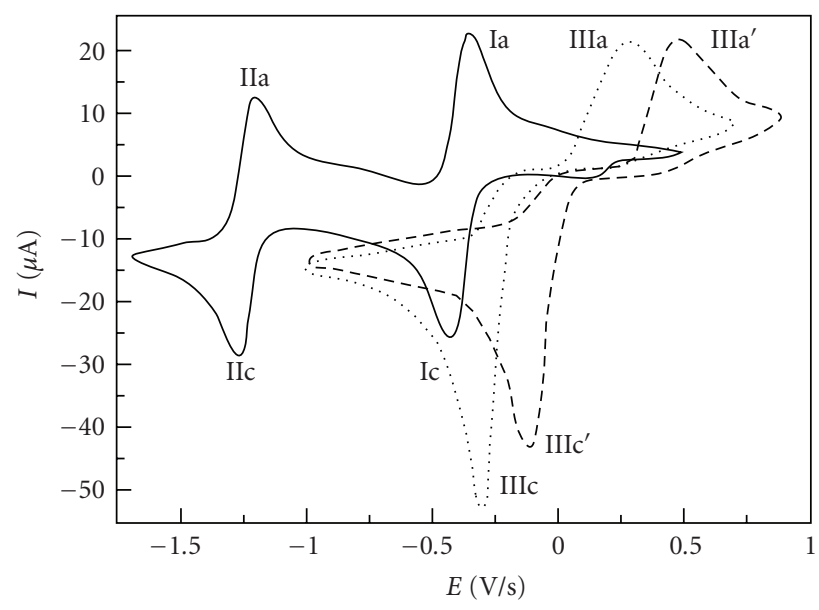

FIGURE 1: Typical cyclic voltammetry of $2.0 \mathrm{mM}$ 1,4-benzoquinone, in $\mathrm{DMSO}+0.2 \mathrm{M} \mathrm{Bu}_{4} \mathrm{NPF}_{6}$, on glassy carbon electrodes $(\phi 3 \mathrm{~mm})$ at $0.1 \mathrm{~V} \mathrm{~s}^{-1}$. Several concentrations of benzoic acid were used: (solid line) $0.0 \mathrm{M}$; (dotted line) $0.03 \mathrm{M}$ and (dashed line) $1.00 \mathrm{M}$. [174].

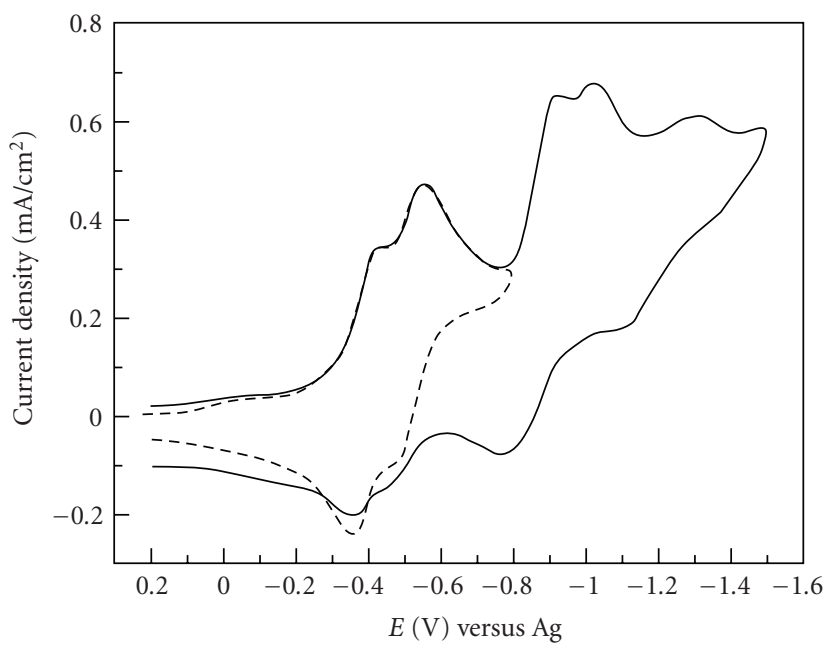

FIgURE 2: CVs for reduction of $1 \mathrm{mM} C \mathrm{CQ}$ at a GC electrode in rigorously dried $\mathrm{CH}_{3} \mathrm{CN}$ containing $0.10 \mathrm{M} \mathrm{TBAPF}_{6}$ as a supporting electrolyte. The scan rate was $100 \mathrm{mV} / \mathrm{s}$. [175].

groups in different nonaqueous solvent-like acetonitrile [177], dimethylformamide [178] and dichloromethane [179] and it was observed the mode of reduction in different studies are almost the same.

Like 1,4-benzoquinone the 3,5-di-tert-butyl-1s,2-benzoquinone $(\mathrm{Q})$ undergoes conventional two-proton twoelectron reduction in acetonitrile [180] However, it was seen that in case of long-term experiments such as controlled potential electrolysis, the semiquinone $\left(\mathrm{Q}^{\bullet-}\right)$ formed disappears slowly. The rate of disappearance was seen to increase with addition of water. The water molecule promotes disproportionation of the semiquinone to neutral quinone (Q) and protonated dianion $\left(\mathrm{HQ}^{-}\right)$and hydroxide. In presence of water $1: 1$ hydrogen bonded complex formation between semiquinone and water molecule $\left[\left(\mathrm{Q}^{\bullet-}\right)\left(\mathrm{H}_{2} \mathrm{O}\right)\right]$ was proposed to form after semiquinone formation. Due to 
such complex formation addition of water changes the standard potential for the first step. The 1:1 complex, $\left[\left(\mathrm{Q}^{\bullet-}\right)\left(\mathrm{H}_{2} \mathrm{O}\right)\right]$, is proposed to be the reactant in the second step of the reduction and it was suggested that the reaction is an electron and proton transfer reaction in which insertion of the electron into the complex is associated with transfer of a proton from water to the developing quinone dianion.

Role of intramolecular hydrogen bonding in reduction has been extensively studied on naphthazarin $(5,8$ dihydroxy-1,4-naphthoquinone) and quinizarin (1,4dihydroxy-9,10-anthraquinone) [181-184]. Additionally, intramolecular hydrogen bonding in the one- and two-electron reduction states of hydroxy-naphthoquinones has been studied by electrochemistry and electron spin resonance $[185,186]$. Intramolecular hydrogen bonding in $\beta$-phenolic quinones cause its electrochemical behavior to be different from $\alpha$-phenolic quinones and intramolecular hydrogen bonding in $\beta$-phenolic quinones stabilize semiquinone and quinone dianion formed by the reduction. Owing to this stabilization the successive reduction potentials will be shifted to more positive potentials $[72,164,167,173]$. By taking different $\beta$-hydroxy naphthoquinones and anthraquinones Gendell et al. [186] have proved that $\beta$-hydroxy quinones produce stable semiquinones. The stabilization arises due to strong hydrogen bonding. It has been found that peak potentials shift towards less negative direction for $\alpha$ - and $\beta$-isomers compared to naphthoquinone except the second reduction peak for $\alpha$-isomer which is shifted towards more negative direction. This indicates that the semiquinone and quinone dianion formed on reduction are stabilized by intramolecular hydrogen bonding. The exceptional behavior of $\alpha$-isomer has been assumed to be due to a self-protonation pathway. To explain the role of hydrogen bonding, intramolecular hydrogen bonding energy of $\beta$-isomers was considered [187] and the same for $\alpha$-isomer was determined and compared. Intramolecular hydrogen bonding increases along the order: 2-hydroxy-1,4-naphthoquinone $<5$-hydroxy-1,4naphthoquinone $<2,5$-dihydroxy-1,4-naphthoquinone. The intramolecular hydrogen bonding diminishes the chemical resistance to the formed semiquinone and influences the disproportionation reaction of semiquinone to quinone and quinone dianion. The disproportionation constant decreases as 2,5-dihydroxy-1,4-naphthoquinone $>5$ hydroxy-1,4-naphthoquinone > 1,4-naphthoquinone.

In dimethylsulphoxide and acetonitrile media the electrochemical reduction of 1,4-naphthoquinone, 5-hydroxy1,4-naphthoquinone, and 5,8-dihydroxy-1,4-naphthoquinone and the effect of acidic additives like benzoic acid and methanol have been studied by Gómez et al. [165]. In both dimethylsulphoxide and acetonitrile it has been seen that as the number of $\alpha$-phenolic groups increase the stabilization of the quinone anions and the reduction potentials shift to more positive values. This means that the energy required to reduce the neutral quinones and the radical anions follows the order: $\mathrm{H}_{2} \mathrm{NQ}<\mathrm{HNQ}<\mathrm{NQ}$, which accounts for the greater stability of the electrochemically generated semiquinone radical: $\mathrm{H}_{2} \mathrm{NQ}^{\circ-}>\mathrm{HNQ}^{\circ-}>\mathrm{NQ}^{\circ-}$ and quinone dianion: $\mathrm{H}_{2} \mathrm{NQ}^{2-}>\mathrm{HNQ}^{2-}>\mathrm{NQ}^{2-}$.

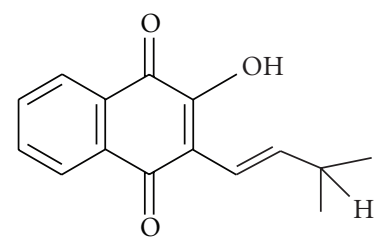

Isolapachol

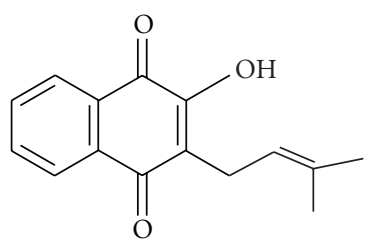

Lapachol
Scheme 9: Structures of isolapachol and lapachol.

The cyclic voltammogram of isolapachol (ISOH) (2-hydroxy-3-(3-methyl-1-butenyl)-1, 4-naphthoquinone) (Scheme 9) [159] in DMF shows two main pairs of peaks, the first cathodic one, designated as Ic at $-0.635 \mathrm{~V}$, with a related anodic peak (Ia) at $-0.103 \mathrm{~V}$ and the second pair, named IIIc at $-1.434 \mathrm{~V}$ and IIIa at $-1.305 \mathrm{~V}$. The first step is irreversible while the second step is quasi-reversible (Figures 3 and 4). An intermediate shoulder (IIc) at $-1.228 \mathrm{~V}$ and a prominent anodic wave ( $\mathrm{Va}$ ) at $+0.900 \mathrm{~V}$ were observed. When the run is in the negative direction and was reversed from $-1.50 \mathrm{~V}$, then an additional anodic wave (IVa) at $+0.488 \mathrm{~V}$ was observed suggesting it (IVa) is related to the oxidation of the product generated at IIIc (Figure 3 ). When the run is in the positive direction, one additional reduction peak at $-0.358 \mathrm{~V}$ was observed and the anodic peak Va shifts to $+0.931 \mathrm{~V}$ (Figure 4). Then the wave IVa vanishes since suggesting that it is related to oxidation of a modified product generated at IIIc. The first reduction peak is due to the generation of the semiquinone $\left(\mathrm{ISOH}_{2}{ }^{--}\right)$. The shoulders are related to the reduction of hydrogen-bonded intermediates and the last quasi-reversible reduction is due to the reduction of the semiquinone. After the generation of semiquinone $\left(\mathrm{ISOH}^{--}\right)$(5a), self-protonation occurs generating $\mathrm{ISOH}_{2}{ }^{\bullet}$ and $\mathrm{ISO}^{-}(5 \mathrm{~b}) . \mathrm{ISOH}_{2}{ }^{\bullet}$ receives a second electron forming the related anion $\left(\mathrm{ISOH}_{2}{ }^{-}\right)$, which suffers a second self-protonation leading to the electroinactive specie $\mathrm{ISOH}_{3}$ (toward reduction), together with $\mathrm{ISO}^{-}(5 \mathrm{~d})$. Thus, the oxidation of the species electrogenerated at Ic occurs at a more positive potential (Ia) due to a lesser electronic density caused by the protonation. That is the reason for the significant separation of waves Ic and Ia $\left(\Delta E_{p}=+0.532 \mathrm{~V}\right)$. Alternatively, the generated radical $\left(\mathrm{ISOH}_{2}{ }^{\bullet}\right)$ undergoes disproportionation to produce original quinone (ISOH) and the anion $\left(\mathrm{ISO}^{-}\right)$, that forms an acid-base homoconjugated dimer. The hydrogen-bonded complex is then reduced in the region of the shoulders. The electrochemical behavior of isolapachol, lapachol (2-hydroxy-3-(3-methyl-2-butenyl)1,4-naphthoquinone), and other analogues of 2-hydroxy-3alkylnaphthoquinones are almost similar. A series of natural and synthetic2-hydroxy-3-alkylnaphthoquinones in DMF have been studied by Ferraz et al. [188]. It was observed that the first cathodic reduction for isolapachol is more positive compared to lapachol. This positive shift in the potential of the first wave of isolapachol, in comparison to lapachol, is related to the higher acidity of the phenolic group in isolapachol. Isolapachol has a conjugated double 
bond, which allows a better stabilization of the conjugated base, through resonance. Itoh et al. [156] have seen similar behaviour observed for pyrroloquinolinequinone. The anodic peak Va is related to the irreversible oxidation of the enolic function, leading probably to an extra quinone group, releasing protons

$$
\begin{aligned}
\mathrm{ISOH}+\mathrm{e} & \rightleftharpoons \mathrm{ISOH}^{\bullet-} \\
\mathrm{ISOH}^{--}+\mathrm{ISOH} & \rightleftharpoons \mathrm{ISOH}_{2}{ }^{\bullet}+\mathrm{ISO}^{-} \\
\mathrm{ISOH}_{2}{ }^{-}+\mathrm{e} & \rightleftharpoons \mathrm{ISOH}_{2}{ }^{-} \\
\mathrm{ISOH}_{2}{ }^{-}+\mathrm{ISOH} & \rightleftharpoons \mathrm{ISOH}_{3}+\mathrm{ISO}^{-}
\end{aligned}
$$

The electrochemical reduction of $\beta$-lapachone and its 3 -sulphonate salt was studied by cyclic, square wave, and differential pulse voltammetry in aqueous and water-ethanol mixtures using a glassy carbon electrode $[189,190]$. Cyclic voltammograms of $\beta$-lapachones at a glassy carbon electrode show a reversible process involving the same number of electrons and protons, and the reduction potential of $\beta$ lapachone is dependent on $\mathrm{pH}$ (slope $59 \mathrm{mV}$ per $\mathrm{pH}$ unit). The study was extended to see whether the molecules interact with DNA or L-cysteine and 2-mercaptoethanol. It was found that $\beta$-Lapachones do not interact directly with single or double strand DNA. When L-cysteine was added to the medium, the cathodic peak decreased significantly in size. The anodic peak was also affected and new cathodic peaks appeared. Such modifications of electrochemical reduction were seen to be concentration dependent. At high concentration the color of the reaction solution changed immediately from bright yellow to pale yellow. These effects were attributed to the reaction of $\beta$-lapachone and L-cysteine. A similar behaviour was observed with 2-mercaptoethanol. The electrochemical observation of the reaction of $\beta$ lapachone with L-cysteine and 2-mercaptoethanol corroborates results obtained and constitute additional evidence for the anticancer activity of $\beta$-lapachones [191, 192].

The electrochemical behavior of a few 9,10-anthraquinone derivatives was studied in acetonitrile solution using cyclic voltammetry by Shamsipur et al. [121]. The results are similar to the behavior of other anthraquinones as reported earlier. They have correlated the experimental data with theoretical data obtained by quantum theoretical calculations. A linear relationship was observed between the theoretically predicted values and experimentally determined half-wave reduction potentials of the 9,10-anthraquinone derivatives. From this study the authors made two conclusions.

Substitution of the hydrogen on $C_{1}$ position of 9,10anthraquinone by a hydroxy group results in a significant positive shift of peak potential of both the first and second reductions.

Substitution at the $\mathrm{C}_{2}$ position revealed some shift in peak potentials, either positive or negative, depending on the nature of the substituted group. However, the extent of shift in potential is not as significant as that observed in case of substitution on $\mathrm{C}_{1}$.

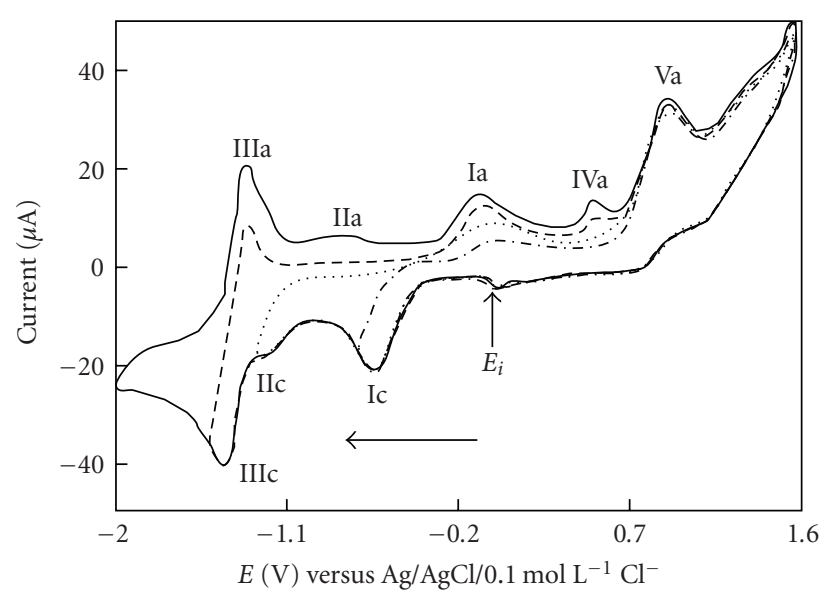

Figure 3: Cyclic voltammograms of isolapachol, DMF + $0.1 \mathrm{~mol} \mathrm{~L}^{-1}$ TBAP, GCE versus $\mathrm{Ag} / \mathrm{AgCl} / 0.1 \mathrm{~mol} \mathrm{~L}^{-1} \mathrm{NaCl}, c=2$ $\mathrm{mmol} \mathrm{L}{ }^{-1}$. (solid line), Initial potential $=0 \mathrm{~V}, v=0: 100 \mathrm{Vs}^{-1}$. Negative scan. different $E_{\lambda}$ : (dashed dotted line) $-0.739 \mathrm{~V}$; (dotted line) $-1.249 \mathrm{~V}$; (dashed line) $-1.519 \mathrm{~V}$ [159].

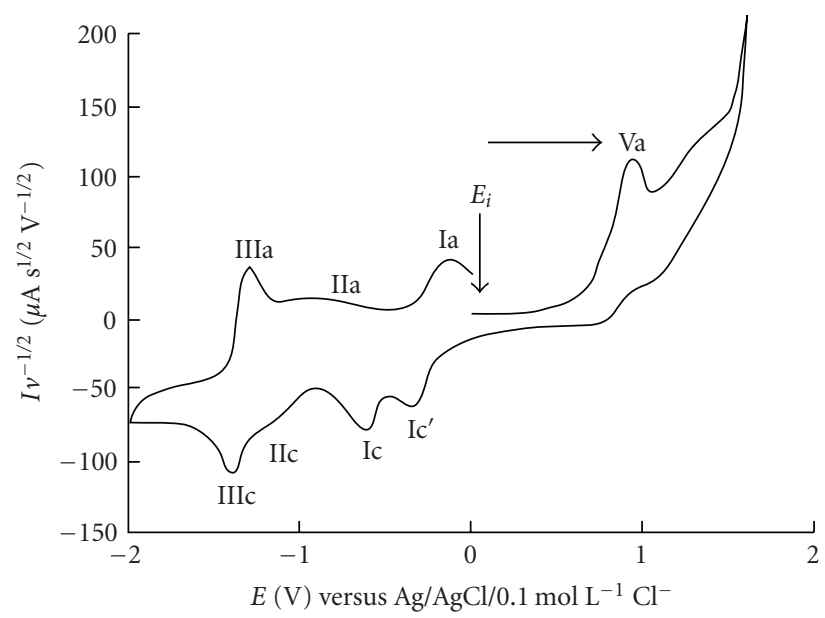

FIgURE 4: Cyclic voltammogram of isolapachol, DMF $+0.1 \mathrm{~mol} \mathrm{~L}^{-1}$ TBAP, GCE versus $\mathrm{Ag} / \mathrm{AgCl} / 0.1 \mathrm{~mol} \mathrm{~L}^{-1} \mathrm{NaCl}, c=2 \mathrm{mmol} \mathrm{L}^{-1}$. Initial potential $=0 \mathrm{~V}, v=0: 100 \mathrm{Vs}^{-1}$. Positive Scan [159].

In nonaqueous solvents addition of weak hydrogen bonding agents like methanol, ethanol, 2-propanol, tertbutanol, and so forth, or strong hydrogen bonding agents like trifluoroethanol can also stabilize the semiquinone radical and the quinone dianion by forming intermolecular hydrogen bonds. Therefore, in presence of such hydrogen bonding agents the two reduction potentials shift towards more positive potential [110, 193-195]. Effect of weak acid like hexafluoro-2-propanol or strong acid like trifluoroacetic acid is almost similar to hydrogen bonding agents. In organic solvents such as DMF, DMSO, and acetonitrile the dissociation of acids is not facile and this is why in such solvents different acids usually cannot protonate the dianion, rather they form hydrogen bonding with the dianion and stabilizes it. Addition of another hydrogen bonding agent water to nonaqueous solvents also changed the reduction potentials and peak current considerably [195]. Gradual addition of 
water to dimethylformamide (DMF) or dimethylsulphoxide (DMSO) solution leads to positive displacement of the second reduction potential until the second wave merges with the first owing to stabilization of the dianion by hydrogen bonding with water molecule [193-198]. It was found that in aqueous dimethylformamide solvent, $\mathrm{pH}$ determines nature of reduction, that is, whether reduction is single step twoelectron or two-step one-electron [77]. For sodium 1,4dihydroxy-9,10-anthraquinone-2-sulphonate at neutral $\mathrm{pH}$ in 95\% DMF the two successive reduction waves (observed in pure DMF) did not appear and a single step two-electron wave was observed. It was found that at $\mathrm{pH} 9.0$ two successive one-electron reduction waves were observed in solution having 40\% DMF [77]. Similar nature of reduction was observed by Masson et al. [199]. They observed that in anhydrous hydrofluoric acid media quinones are reducible in two monoelectronic reversible steps. However, in hydrogen fluoride-water mixtures, the classical one-step two-electron reduction was found [199].

In acetonitrile media, electrochemical behavior of 2,3,5-trimethyl-6-(3'-methyl-3'-hydroxybutyl) quinone was changed significantly by the addition of a weak acid like ethyl malonate [150]. Though the first reduction was unaltered, the second reduction peak broadened, shifted anodically and became irreversible. The corresponding oxidation peak therefore disappeared. In order to explain this result the following mechanism was proposed:

$$
\begin{gathered}
\mathrm{Q}+\mathrm{e} \rightleftharpoons \mathrm{Q}^{\bullet-} \\
\mathrm{Q}^{--}+\mathrm{e} \rightleftharpoons \mathrm{Q}^{2-} \\
\mathrm{Q}^{2-}+\mathrm{HA} \rightleftharpoons \mathrm{QH}^{-}+\mathrm{A}^{-} \\
\mathrm{QH}^{-}+\mathrm{Q} \rightleftharpoons 2 \mathrm{Q}^{--}+\mathrm{H}^{+}
\end{gathered}
$$

where HA is a proton donor. The protonation of the dianion $\mathrm{Q}^{2-}$ is fast relative to potential sweep and the protonated specie $\left(\mathrm{QH}^{-}\right)$readily undergoes comproportionation reaction with $(\mathrm{Q})$ to produce a semiquinone $\left(\mathrm{Q}^{\bullet-}\right)$. Therefore, the oxidation peak corresponding to quinone dianion to quinone disappears.

In presence of stronger proton donors like benzenethiol, the cathodic process is an overall two-electron process and protonation of semiquinone is an important part of the mechanism [150]. The reduction of quinone to semiquinone shifts anodically and doubles in height, while the cathodic wave for the reduction of semiquinone to quinone dianion disappears.

To explain the phenomena the following scheme was proposed:

$$
\begin{gathered}
\mathrm{Q}+\mathrm{e} \rightleftharpoons \mathrm{Q}^{\bullet-} \mathrm{E}_{1} \\
\mathrm{Q}^{\bullet-}+\mathrm{HA} \rightleftharpoons \mathrm{QH}^{\bullet}+\mathrm{A}^{-} \\
\mathrm{QH}^{\bullet}+\mathrm{e} \rightleftharpoons \mathrm{QH}^{-} \mathrm{E}_{2} \quad\left(\text { where, } \mathrm{E}_{2}>\mathrm{E}_{1}\right) \\
\mathrm{Q}^{\bullet-}+\mathrm{QH}^{\bullet} \rightleftharpoons \mathrm{Q}+\mathrm{QH}^{-}
\end{gathered}
$$

Quinones having phenolic hydroxy group at $\alpha$-position, that is quinones capable of forming intramolecular hydro- gen bonding in the neutral molecule or in the anionic form, show different electrochemical behaviors in nonaqueous solvent on addition of acetic acid. Gómez et al. [165] compared the electrochemical behavior of 1,4-naphthoquinone (NQ), 5-hydroxy-1,4-naphthoquinone (HNQ), and 5,8-dihydroxy-1,4-naphthoquinone $\left(\mathrm{H}_{2} \mathrm{NQ}\right)$. In 1,4-naphthoquinone intramolecular hydrogen bonding is absent and cyclic voltammetry experiment showed a transition from one-electron to two-electron reduction of the molecule with increase in acetic acid. In presence of acid, the semiquinone formed $\left(\mathrm{NQ}^{\bullet-}\right)$ was converted to the protonated radical anion $\left(\mathrm{NQH}^{\bullet}\right)$ that was more easily reduced than the neutral quinone NQ. As a result the first and second reductions occur at almost same potential and the overall reduction was observed to be by one step two electrons. A similar behavior of quinones was also described by Gupta and Linschitz [110] and Chambers [2,3]. Cyclic voltammetry experiments of $\mathrm{H}_{2} \mathrm{NQ}$ in presence of different concentrations of acetic acid showed that the chemical reversibility of the two one-electron waves are not lost suggesting typical protonation reactions are inhibited, even at an $\mathrm{HAc} / \mathrm{H}_{2} \mathrm{NQ}$ concentration ratio close to 200. This effect was explained by considering that the radical anion $\mathrm{H}_{2} \mathrm{NQ}^{\cdot-}$ and dianion $\mathrm{H}_{2} \mathrm{~N}$ formed in the first and second electron transfer steps are highly stabilized by the presence of two intramolecular hydrogen bonds and that it did not undergo any form of external protonation. This observed voltammetric behavior of $\mathrm{H}_{2} \mathrm{NQ}$ was supported by other workers $[169,200]$. On the other hand, HNQ is an intermediary structure between NQ and $\mathrm{H}_{2} \mathrm{NQ}$. The cyclic voltammetry experiments on HNQ showed a small concentration of acetic acid is required to obtain a reduction wave where apparently first and second reduction waves merged.

The electrochemical properties of quinone-hydroquinone $(\mathrm{Q} / \mathrm{QH} 2)$ systems in acetonitrile and nitromethane media were studied by rotating-disk electrode voltammetry, cyclic voltammetry, controlled potential coulometry and absorption and ESR spectroscopy [201]. Cyclic voltammetry indicated that the reversibility of the redox system Q/QH2 was dependent on the nature of the substituents and the acidity of the medium.

At mercury electrode electroreduction of camphorquinone in DMF was investigated by Ouziel and Yarnitzky [202]. In DMF and in absence of proton donor, the molecule showed two one-electron waves. In the second step the monoanion radical, produced in the first step, was reduced to dianion irreversibly. The irreversibility of the second wave was explained by assuming a fast irreversible protonation of the dianion.

\subsubsection{Effects of Homogeneous Chemical Reactions in Reduction} Process. Besides electrochemical reactions there are other reactions like disproportionation, comproportionation, or dimerization that affect an overall electrochemical reaction. In nonaqueous solvent it has been found that peak current of second reduction was significantly smaller than those of the first and that the second reduction peak deviates considerably than those expected for simple two-electron reductions $[4,77,110,114,150,203-206]$. One of the largest 
deviation from ideality was seen in ortho-benzoquinone, 3,5-di-tert-butyl-1,2-benzoquinone. In such compounds, it was found that the second reduction peak is almost one fourth of that expected [121]. It hints at the fact that the concentration of quinone dianion decreases by some other homogeneous chemical process $[77,122,133$, 207, 208]. In some works, it was explained assuming a comproportionation reaction between the quinone dianion and the quinone to form the semiquinone radical. The comproportionation was further established by Guin et al. [77] who found that in pure DMF, when the scan is reversed after sufficient time elapsed following the second reduction the anodic peak current for the first reduction is markedly increased than when the scan is reversed before the second reduction. This increase in anodic peak current indicates that the semiquinone concentration increases when there is a scope for second reduction. The decrease of the second reduction peak was explained by Lehman and Evans [122] who suggested a fast and irreversible dimerization reaction in between quinone dianion $\left(\mathrm{Q}^{2-}\right)$ and quinone (Q) to form an electroinactive dimeric species $\mathrm{Q}_{2}{ }^{2-}$ in acetonitrile media. Simulation studies carried out could prove these types of reactions [77, 122]. In different alcohols, Wipf et al. [133] had shown that different anthraquinone compounds would generate two one-step reduction process and difference in the two reduction potentials decreases in the order: 2-propanol > ethanol > methanol > water. In basic methanol and in basic aqueous solution actually only one reduction peak was found and two one-electron peaks merge as their peak potential difference is very small $[207,208]$. From pulse radiolysis experiments it has been found that the difference between the reduction potential of quinone and the semiquinone is $9 \mathrm{mV}$ [65]. Wipf et al. [133] showed that at very high $\mathrm{pH}$ in protic solvents, protonation is unimportant and the electron-transfer processes would be affected by electron-transfer kinetics and reduction potentials of relevant couples. Under these conditions, the redox chemistry in basic, protic solvents should resemble that found in aprotic solvents [2, 3]. Disproportionation reactions were seen to operate at high $\mathrm{pH}$ in these cases.

During the electrochemical reduction of tetramethyl1,4-benzoquinone (duroquinone), the dimer diduroquinone is produced in high yield. The dimerization is proposed to proceed via a catalytic process as the current passed is much less than one electron per molecule. Diduroquinone is further cleaved to duroquinone anion radical by an electrochemical reduction [203].

Glezer et al. [205] studied electrochemical reduction of intramolecular charge-transfer complexes derived from 1, 4naphthoquinone in DMF and aqueous DMF solutions. In aprotic media electrochemical reduction of the compounds proceeds via two successive steps; the first leads to the formation of a stable anion radical while the second forms an unstable primary product. The hyperfine structures of the corresponding anion radicals were studied.

2.3.3. Role of Cations and Anions of Supporting Electrolytes. In aprotic media the cation of the supporting electrolyte or any added cation is known to form ion pairs with semiquinone and quinone dianion produced by the reduction of quinones $[123,206,209-212]$. During the electrochemical reduction of anthraquinones in dimethylformamide the ion pairs of anthraquinone anions were examined where it was found that the ion-pairs were adsorbed on $\mathrm{Hg}$ electrodes in the presence of divalent metal ions while the same did not happen at the gold electrode surface. The nature of specific interaction between the semiquinone or quinone dianion and the mercury electrode and possible structure of the ion pairs were also suggested [209].

On addition of metal ions new set of peaks were observed at more positive potential in comparison to the original free ligand wave. This reflects stabilization of the reduced form, radical anion or dianion of diquinone in the presence of metal ions. Such phenomena were seen for quinonefunctionalized calix-[4]-arene where the molecule was found applicable to the fabrication of a molecular device that selectively recognize specific cations $[213,214]$.

Hence, due to ion pair formation reduction potentials were shifted towards positive direction. The extent of such shift depends on the concentration and on ionic potential $\Phi_{\text {eff }}$ of the cation [214-217]. $\Phi_{\text {eff }}$ is defined as $z /(r+\delta)$ where, $z$ and $r$ are the charge and Pauling's radius of cation, respectively, and $\delta$ is Latimer type correction factor. Hence, the greater charge and smaller size of a metal ion causes larger shift in the reduction potential [153]. Chung et al. [153] have established that the extent of positive shift of reduction potential for few analogues of calix-[4]-arene diquinone after complexation with a series of metal ions follows the order: $\mathrm{La}^{3+}>\mathrm{Mg}^{2+}>\mathrm{Ca}^{2+}>\mathrm{Li}^{+}>\mathrm{Na}^{+}>\mathrm{K}^{+}$. Peover and Davies [215] have shown that in dimethylformamide for anthraquinone, para-benzoquinone, and chloranil the extent of association of quinone dianion with cation decreases with decreasing positive charge density on the cation and established the decreasing order of association as $\mathrm{Li}^{+}>\mathrm{Na}^{+}>$ $\mathrm{K}^{+}>\mathrm{NEt}_{4}^{+}>\mathrm{NBu}_{4}^{+}$. Stoichiometries of such ionic associations are also dependent on the nature of the cation [215]. Metal ion complexes can be considered to undergo a transition of the nature of a host-guest interaction during electrochemical reduction. Ion-dipole interaction is predominant in the neutral ligand complex, but ion-ion interaction or electrostatic interaction becomes an overwhelming factor after electrochemical electron donation. The extent of positive shift of electrode potential is used to determine the association constant, stoichiometry of ion-pair association and thermodynamic parameters [209, 216, 217].

The standard rate constants $k_{1}^{\circ}$ and $k_{2}^{\circ}$ of the electron transfer between para-benzoquinone and its radical and of the radical anion and the hydroquinone dianion have been measured by means of cyclic voltammetry at a plain gold electrode in different aprotic solvents. Four different tetraalkylammonium perchlorates were used as supporting electrolytes. Using standard electrode potentials the association constants of the hydroquinone dianion and the cation of the supporting electrolyte were calculated. The association constants and the observed Gibbs activation energies decrease with increasing size of supporting electrolyte cation [209]. 
To observe the solvent effect on ion-pair association, Oyama et al. [206] have analyzed the ion-pair formation between 2,3,5,6-tetrachloro-1,4-benzoquinone anion radical and $\mathrm{Mg}^{2+}$ in different solvents using pulse electrolysis stopped flow method. It was shown that interaction between semiquinone and $\mathrm{Mg}^{2+}$ in acetonitrile was much stronger than in DMF and DMSO which could be explained by the difference in solvating power for the cationic species [4]. The solvation of acetonitrile for $\mathrm{Mg}^{2+}$ is assumed to be so weak as to let 2,3,5,6-tetrachloro-1,4-benzoquinone interact with $\mathrm{Mg}^{2+}$. The semiquinone formed by one-electron reduction exists in free state in DMF and DMSO even when a large excess of $\mathrm{Mg}^{2} \div$ is present. Therefore, the interactions of DMF and DMSO with $\mathrm{Mg}^{2} \div$ are found to be stronger than that between semiquinone and $\mathrm{Mg}^{2} \div$, though the latter is a coulombic interaction. The competing interactions of DMF (or DMSO) and semiquinone for $\mathrm{Mg}^{2} \div$ could also be observed in the kinetic measurements. Pulse electrolysis stopped flow method also showed that in spite of complex electrochemical responses, the kinetic processes dominate the ion pair formation between 2,3-dichloro-5,6-dicyano1,4-benzoquinone dianion and $\mathrm{Na}^{\circ}$ [206].

The values of heterogeneous electron transfer rate constants for the reduction of different quinones in nonaqueous solvents at different electrodes have been measured by cyclic voltammetry [217]. Theoretically, the redox potentials have been calculated including solvent effect, for a series of anthraquinone and few other quinone derivatives by Alizadeh and Shamsipur [218] and compared with the available experimental electrode potentials [122] in two consecutive electron transfer steps in acetonitrile solution. The theoretical values of redox potentials in the two successive one-electron steps in most cases show a relatively good agreement with the corresponding experimental electrode potentials [218].

A recent report on electrochemical behavior of a $\mathrm{Cu}(\mathrm{II})$ complex of sodium 1,4-dihydroxy-9,10-anthraquinone-2sulphonate shows that upon complex formation the electrochemical behavior of such molecules is significantly modified. In dimethylformamide solvent the $\mathrm{Cu}$ (II) complex of sodium 1,4-dihydroxy-9,10-anthraquinone-2-sulphonate shows only one reversible reduction peak corresponding to one-electron reduction of the complex [219].

\subsection{Electrochemical Reduction of Quinones in Oxygenated} Nonaqueous Solutions. In oxygenated nonaqueous solvent anthraquinones mediate one-electron reduction of oxygen to superoxide anion radical as follows. At first quinone (Q) is reduced to semiquinone $\left(\mathrm{Q}^{\bullet-}\right)$ by one-electron reduction. In presence of oxygen the semiquinone formed reacts with molecular oxygen to form a complex $\left(\mathrm{QO}_{2}{ }^{--}\right)$which then breaks to anthraquinone $(\mathrm{Q})$ and superoxide anion radical $\left(\mathrm{O}_{2}{ }^{--}\right)[220-224]$

$$
\begin{gathered}
\mathrm{Q}+\mathrm{e} \longrightarrow \mathrm{Q}^{\bullet-} \\
\mathrm{Q}+\mathrm{O}_{2} \longrightarrow \mathrm{QO}_{2}^{\cdot-} \\
\mathrm{QO}_{2}^{\cdot-} \longrightarrow \mathrm{Q}+\mathrm{O}_{2}^{\cdot-}
\end{gathered}
$$

An alternative mechanism was also proposed in which the first step involves the formation of an adduct between singlet oxygen to anthraquinone. In the second step the adduct is reduced by one electron and it then dissociates to anthraquinone and superoxide radical [225-229]

$$
\begin{gathered}
\mathrm{Q}+\mathrm{O}_{2} \longrightarrow \mathrm{QO}_{2} \\
\mathrm{QO}_{2} \longrightarrow \mathrm{QO}_{2}{ }^{\cdot-} \\
\mathrm{QO}_{2}^{\cdot-} \longrightarrow \mathrm{Q}+\mathrm{O}_{2}{ }^{\bullet-}
\end{gathered}
$$

It has been observed that in nonaqueous media hydroxyanthraquinones catalyze the reduction of molecular oxygen significantly in comparison to that of anthraquinones without hydroxy group. This phenomenon has been explained by the assumption that anthraquinone reduction is accompanied with oxygen addition to form hydroperoxide anion radicals, which can be formed by anthraquinones having proton-donor like hydroxy groups only. This observation has been justified theoretically and experimentally [230].

\section{Conclusions}

Quinones undergo one-step two-electron reduction in aqueous buffer at acidic, neutral, and alkaline $\mathrm{pH}$ generating one reversible reduction wave. However, at acidic $\mathrm{pH}$ the reduction involves two protons while at alkaline $\mathrm{pH}$ the reduction does not involve any proton. In neutral $\mathrm{pH}$, the reduction may or may not involve proton depending upon the $\mathrm{pK}$ value of the phnolic $-\mathrm{OH}$ group of the hydroquinone. In acidic and neutral $\mathrm{pH}$, quinizarin $(1,4-$ dihydroxy-9,10-anthraquinone) and some of its analogues such as quinizarin-2-sulphonate, adriamycin, and daunorubicin show another irreversible reduction peak at much more negative potential, but such reduction peak was not observed in case of pure anthraquinone. Thus it was suggested that presence of two adjacent hydroquinone moieties is essential for such a reduction peak and was proposed to be due to hydrogen evolution. In case of adriamycin, in addition to the above two peaks at $\mathrm{pH} 4.5$ a reversible anodic peak at $+500 \mathrm{mV}$ was observed which has been assigned as the redox process involving the oxidation of the hydroquinone group of dihydroxy-9,10-anthraquinone moiety. In unbuffered media, when proton concentration is similar to that of the quinone then the reduction is a single-step two-electron two-proton reduction. When the proton concentration is small then depending upon the pKs of hydroquinone neutral, anionic, and dianionic species are generated. In nonaqueous media, the reduction of quinones takes place by two successive one-electron reduction steps in which the first step is completely reversible, while the second step quasi-reversible at customary scan rates. In the first step, the quinone becomes semiquinone and in the second step the semiquinone becomes quinone dianion. The two reduction steps are greatly influenced by nature of the solvents, intramolecular hydrogen bonding, protonationdeprotonation equilibrium, addition of acidic or basic additives or even addition of water, ion-pair formation, nature of supporting electrolyte, polarity of solvents and so forth. 
Introduction of hydroxy groups at 5- and 8-positions of the 1,4-naphthoquinone nucleus and 1-, 4-, 5- and 8-positions of the 9,10-anthraquinone nucleus enable the formation of hydrogen bond with semiquinone radical and quinone dianion that increases their reduction potentials. Hydrogen bond was also observed in case of semiquinones, quinone dianions with added proton sources such as acids, alcohols, and water which shift the reduction potential towards positive directions. Besides electrochemical reactions there were other homogeneous chemical reactions like disproportionation, comproportionation, or dimerization that affect the overall electrochemical reaction. In nonaqueous media the cation of the supporting electrolyte or any added cation was known to form ion pairs with semiquinone and quinone dianion. Owing to ion-pair formation reduction potentials were shifted towards positive direction. In oxygenated nonaqueous solvents, quinones mediate one-electron reduction of oxygen to superoxide anion radical by different mechanisms but itself remains unaltered. All such effects in the reduction of quinones in aqueous and nonaqueous solvents have been summarized and correlated with electrode potentials.

\section{Acknowledgments}

The authors are grateful to American Chemical Society for giving the permission to reuse a figure from [175] and Elsevier to reuse a figure from [174] and two figures from [159].

\section{References}

[1] L. P. Fieser, "The tautomerism of hydroxy quinones," Journal of the American Chemical Society, vol. 50, no. 2, pp. 439-465, 1928.

[2] J. Q. Chambers, "Electrochemistry of quinones," in The Chemistry of Quinonoid Compounds, S. Patai and Z. Rappoport, Eds., vol. 2, chapter 12, pp. 719-757, Wiley, New York, NY, USA, 1988.

[3] J. Q. Chambers, "Electrochemistry of quinones," in The Chemistry of Quinonoid Compounds, S. Patai and Z. Rappoport, Eds., vol. 1, chapter 14, pp. 737-791, Wiley, New York, NY, USA, 1974.

[4] M. E. Peover and A. J. Bard, Eds., Electrochemical Chemistry, vol. 2, Marcel Dekker, New York, NY, USA, 1967.

[5] P. Zuman, Substituent Effect on Organic Polarography, chapter 8, Plenum Press, New York, NY, USA, 1967.

[6] J. S. Jaworski, E. Leniewska, and M. K. Kalinowski, "Solvent effect on the redox potential of quinone-semiquinone systems," Journal of Electroanalytical Chemistry, vol. 105, no. 2, pp. 329-334, 1979.

[7] C. Rüssel and W. Janicke, "Heterogeneous electron exchange of quinones in aprotic solvents. Part III. The second reduction step of p-benzoquinone and its dependence on the supporting electrolyte," Journal of Electroanalytical Chemistry, vol. 199, no. 1, pp. 139-151, 1986.

[8] E. Laviron, "Electrochemical reactions with protonations at equilibrium. Part XIII. Experimental study of the homogeneous electron exchange in quinone/dihydroquinone systems," Journal of Electroanalytical Chemistry, vol. 208, no. 2, pp. 357-372, 1986.
[9] J. H. Wilford and M. D. Archer, "Solvent effects on the redox potentials of benzoquinone," Journal of Electroanalytical Chemistry, vol. 190, no. 1-2, pp. 271-277, 1985.

[10] S. I. Bailey and I. M. Ritchie, "A cyclic voltammetric study of the aqueous electrochemistry of some quinones," Electrochimica Acta, vol. 30, no. 1, pp. 3-12, 1985.

[11] S. I. Bailey, I. M. Ritchie, and F. R. Hewgill, "The construction and use of potential-pH diagrams in organic oxidationreduction reactions," Journal of the Chemical Society, Perkin Transactions 2, no. 5, pp. 645-652, 1983.

[12] L. Jeftic and G. Manning, "A survey on the electrochemical reduction of quinones," Journal of Electroanalytical Chemistry, vol. 26, no. 2-3, pp. 195-200, 1970.

[13] J. Hanzlik and Z. Samec, "Influence of protons on electrochemical behavior of the system quinone-hydroquinone in dichlorethane," Collection of Czech Chemical Communications, vol. 50, pp. 2821-2826, 1985.

[14] M. Bauscher and W. Mäntele, "Electrochemical and infraredspectroscopic characterization of redox reactions of $\mathrm{p}$ quinones," Journal of Physical Chemistry, vol. 96, no. 26, pp. 11101-11108, 1992.

[15] J. Jacq, "Reactions chimiques et electrochimiques couplees en regime stationnaire-II. Systemes redox consecutifs," Electrochimica Acta, vol. 12, no. 9, pp. 1345-1361, 1967.

[16] J. F. Coetzee and C. W. Gardner Jr., "Exchange current densities and other properties of reference electrodes based on the triiodide-iodide and silver(I) ion-silver couples in organic solvents," Analytical Chemistry, vol. 54, no. 14, pp. 2530-2532, 1982.

[17] K. Sasaki, T. Kashimura, M. Ohura, Y. Ohsaki, and N. Ohta, "Solvent effect in the electrochemical reduction of pquinones in several aprotic solvents," Journal of the Electrochemical Society, vol. 137, no. 8, pp. 2437-2443, 1990.

[18] W. A. Cramer and D. B. Knaff, in Energy Transduction in Biological Membranes, C. R. Cantor, Ed., chapter 4, Springer, New York, NY, USA, 1990.

[19] R. A. Morton, Ed., Biochemistry of Quinones, Academic Press, New York, NY, USA, 1965.

[20] A. J. Swallow, "Physical chemistry of quinones," in Functions of Quinones in Energy Conserving Systems, B. L. Trumpower, Ed., chapter 2, Academic Press, New York, NY, USA, 1982.

[21] B. L. Trumpower, "The protonmotive Q cycle. Energy transduction by coupling of proton translocation to electron transfer by the cytochrome bc complex," Journal of Biological Chemistry, vol. 265, no. 20, pp. 11409-11412, 1990.

[22] M. Y. Okamura and G. Feher, "Proton transfer in reaction centers from photosynthetic bacteria," Annual Review of Biochemistry, vol. 61, pp. 861-896, 1992.

[23] S. T. Crooke and S. D. Reich, Anthracycline: Current Status and New Developments, Academic Press, New York, NY, USA, 1980.

[24] F. M. Muggia, C. W. Young, and S. K. Carter, Anthracycline Antibiotics in Cancer Therapy, The Hauge, 1982.

[25] W. S. Thayer, "Adriamycin stimulated superoxide formation in submitochondrial particles," Chemico-Biological Interactions, vol. 19, no. 3, pp. 265-278, 1977.

[26] K. J. A. Davies, J. H. Doroshow, and P. Hochstein, "Mitochondrial NADH dehydrogenase-catalyzed oxygen radical production by adriamycin, and the relative inactivity of 5iminodaunorubicin," FEBS Letters, vol. 153, no. 1, pp. 227230, 1983. 
[27] N. R. Bachur, S. L. Gordon, and M. V. Gee, "Anthracycline antibiotic augmentation of microsomal electron transport and free radical formation," Molecular Pharmacology, vol. 13, no. 5, pp. 901-910, 1977.

[28] C. E. Myers, W. P. McGuire, and R. H. Liss, "Adriamycin: the role of lipid peroxidation in cardiac toxicity and tumor response," Science, vol. 197, no. 4299, pp. 165-167, 1977.

[29] B. Kalyanaraman, E. Perez-Reyes, and R. P. Mason, "Spintrapping and direct electron spin resonance investigations of the redox metabolism of quinone anticancer drugs," Biochimica et Biophysica Acta, vol. 630, no. 1, pp. 119-130, 1980.

[30] J. W. Lown and G. Weir, "Studies related to antitumor antibiotics. Part XIV. Reactions of mitomycin B with DNA," Canadian Journal of Biochemistry, vol. 56, no. 5, pp. 269-304, 1978.

[31] J. W. Lown, in Reactive Oxygen Species in Chemistry, Biology and Medicine, A. Quintanilha, Ed., pp. 167-185, Plenum Press, New York, NY, USA, 1988.

[32] J. W. Lown, A. V. Joshua, and J. S. Lee, "Molecular mechanisms of binding and single-strand scission of deoxyribonucleic acid by the antitumor antibiotics saframycins A and C," Biochemistry, vol. 21, no. 3, pp. 419-428, 1982.

[33] C. C. Winterbourn, "Evidence for the production of hydroxyl radicals from the adriamycin semiquinone and HO," FEBS Letters, vol. 136, no. 1, pp. 89-94, 1981.

[34] D. A. Bates and C. C. Winterbourn, "Deoxyribose breakdown by the adriamycin semiquinone and HO: evidence for hydroxyl radical participation," FEBS Letters, vol. 145, no. 1, pp. 137-142, 1982.

[35] G. Zbinden, E. Bachmann, and C. Holderegger, "Model systems for cardiotoxic effects of anthracyclines," Antibiotics and Chemotherapy, vol. 23, pp. 255-270, 1978.

[36] H. Beraldo, A. Garnier-Suillerot, L. Tosi, and F. Lavelle, "Iron(III)-adriamycin and iron(III)-daunorubicin complexes: physicochemical characteristics, interaction with DNA, and antitumor activity," Biochemistry, vol. 24, no. 2, pp. 284-289, 1985.

[37] P. K. Dutta and J. A. Hutt, "Resonance Raman spectroscopic studies of adriamycin and copper(II)-adriamycin and copper(II)-adriamycin-DNA complexes," Biochemistry, vol. 25, no. 3, pp. 691-695, 1986.

[38] M. M. L. Fiallo and A. Garnier-Suillerot, "Metal anthracycline complexes as a new class of anthracycline derivatives. $\mathrm{Pd}(\mathrm{II})$-adriamycin and $\mathrm{Pd}(\mathrm{II})$-daunorubicin complexes: physicochemical characteristics and antitumor activity," Biochemistry, vol. 25, no. 4, pp. 924-930, 1986.

[39] A. Di Marco, F. Zunino, R. Silvestrini, C. Gambarucci, and R. A. Gambetta, "Interaction of some daunomycin derivatives with deoxyribonucleic acid and their biological activity," Biochemical Pharmacology, vol. 20, no. 6, pp. 1323-1328, 1971.

[40] J. W. Lown, S. K. Sim, K. C. Majumdar, and R. Y. Chang, "Strand scission of DNA by bound adriamycin and daunorubicin in the presence of reducing agents," Biochemical and Biophysical Research Communications, vol. 76, no. 3, pp. 705-710, 1977.

[41] E. Feinstein, E. Canaani, and L. M. Weiner, "Dependence of nucleic acid degradation on in situ free-radical production by adriamycin," Biochemistry, vol. 32, no. 48, pp. 13156-13161, 1993.

[42] H. Nakashima, N. Yamamoto, Y. Inouye, and S. Nakamura, "Inhibition by doxorubicin of human immuno-deficiency virus (HIV) infection and replication in vitro," Journal of Antibiotics, vol. 40, no. 3, pp. 396-399, 1987.
[43] E. M. Wondrak, J. Lower, and R. Kurth, "Inhibition of HIV-1 RNA-dependent DNA polymerase and cellular DNA polymerase $\alpha, \beta$ and $\gamma$ by phosphonoformic acid and other drugs," Journal of Antimicrobial Chemotherapy, vol. 21, no. 2, pp. 151-161, 1988.

[44] J. W. Lown, "Discovery and development of anthracycline antitumour antibiotics," Chemical Society Reviews, vol. 22, no. 3, pp. 165-176, 1993.

[45] E. Bachmann, E. Weber, and G. Zbinden, "Effects of 7 anthracycline antibiotics on electrocardiogram and mitochondrial function of rat hearts," Agents and Actions, vol. 5, no. 4, pp. 383-393, 1975.

[46] V. J. Ferrans, "Overview of cardiac pathology in relation to anthracycline cardiotoxocity," Cancer Treatment Reports, vol. 62, no. 6, pp. 955-961, 1978.

[47] D. Barasch, O. Zipori, I. Ringel, I. Ginsburg, A. Samuni, and J. Katzhendler, "Novel anthraquinone derivatives with redox-active functional groups capable of producing free radicals by metabolism: Are free radicals essential for cytotoxicity?" European Journal of Medicinal Chemistry, vol. 34, no. 7-8, pp. 597-615, 1999.

[48] A. Di Marco, M. Gaetani, P. Orezzi et al., "'Daunomycin', a new antibiotic of the rhodomycin group," Nature, vol. 201, no. 4920, pp. 706-707, 1964.

[49] H. Muhammed, T. Ramasarma, and C. K. R. Kurup, "Inhibition of mitochondrial oxidative phosphorylation by adriamycin," Biochimica et Biophysica Acta, vol. 722, no. 1, pp. 43-50, 1983.

[50] E. Goormaghtigh and J. M. Ruysschaert, "Anthracycline glycoside-membrane interactions," Biochimica et Biophysica Acta, vol. 779, no. 3, pp. 271-288, 1984.

[51] E. J. F. Demant, "NADH oxidation in submitochondrial particles protects respiratory chain activity against damage by adriamycin-Fe," European Journal of Biochemistry, vol. 137, no. 1-2, pp. 113-118, 1983.

[52] E. J. F. Demant and P. K. Jensen, "Destruction of phospholipids and respiratory-chain activity in pig-heart submitochondrial particles induced by an adriamycin-iron complex," European Journal of Biochemistry, vol. 132, no. 3, pp. 551-556, 1983.

[53] Y. Iwamoto, I. L. Hansen, T. H. Porter, and K. Folkers, "Inhibition of coenzyme Q enzymes, succinoxidase and $\mathrm{NADH}$ oxidase, by adriamycin and other quinones having antitumor activity," Biochemical and Biophysical Research Communications, vol. 58, no. 3, pp. 633-638, 1974.

[54] J. Goodman and P. Hochstein, "Generation of free radicals and lipid peroxidation by redox cycling of adriamycin and daunomycin," Biochemical and Biophysical Research Communications, vol. 77, no. 2, pp. 797-803, 1977.

[55] Y. Kawakami and A. J. Hopfinger, "Prediction of initial reduction potentials of compounds related to anthracyclines and implications for estimating cardiotoxicity," Chemical Research in Toxicology, vol. 3, no. 3, pp. 244-247, 1990.

[56] F. C. de Abreu, P. A. L. De Ferraz, and M. O. F. Goulart, "Some applications of electrochemistry in biomedical chemistry. Emphasis on the correlation of electrochemical and bioactive properties," Journal of the Brazilian Chemical Society, vol. 13, no. 1, pp. 19-35, 2002.

[57] J. W. Lown, H. H. Chen, and J. A. Plambeck, "Further studies on the generation of reactive oxygen species from activated anthracyclines and the relationship to cytotoxic action and cardiotoxic effects," Biochemical Pharmacology, vol. 31, no. 4, pp. 575-581, 1982. 
[58] R. L. Blankespoor, E. L. Kosters, A. J. Post, and D. P. VanMeurs, "Substituent effects upon the peak potentials and reductive cleavage rate constants of hydroxy- and methoxysubstituted 9,10-anthraquinones in 50\% aqueous $\mathrm{CHCN}$ : do they correlate?" Journal of Organic Chemistry, vol. 56, no. 4, pp. 1609-1614, 1991.

[59] A. Kumbhar, S. Padhye, and D. Ross, "Cytotoxic properties of iron-hydroxynaphthoquinone complexes in rat hepatocytes," BioMetals, vol. 9, no. 3, pp. 235-240, 1996.

[60] A. Bartoszek, "Metabolic activation of adriamycin by NADPH-cytochrome P450 reductase; overview of its biological and biochemical effects," Acta Biochimica Polonica, vol. 49, no. 2, pp. 323-331, 2002.

[61] P. Montalbini, "Effect of infection by Uromyces phaseoli (Pers.) Wint. on electron carrier quinones in bean leaves," Physiologial Plant Pathology, vol. 3, no. 4, pp. 437-441, 1973.

[62] F. Arcamone, Doxorubicin Anticancer Antibiotics, Academic Press, New York, NY, USA, 1981.

[63] E. Khadem, Anthracycline Antibiotics, Academic Press, New York, NY, USA, 1982.

[64] D. Meisel and G. Czapski, "One-electron transfer equilibria and redox potentials of radicals studied by pulse radiolysis," Journal of Physical Chemistry, vol. 79, no. 15, pp. 1503-1509, 1975.

[65] D. Meisel and R. W. Fessenden, "Electron exchange and electron transfer of semiquinones in aqueous solutions," Journal of the American Chemical Society, vol. 98, no. 24, pp. 7505-7510, 1976.

[66] T. Mukherjee, E. J. Land, A. J. Swallow, P. M. Guyan, and J. M. Bruce, "Successive addition of electrons to sodium quinizarin-2- and -6-sulphonate in aqueous solution. A pulse and $\gamma$-radiolysis study," Journal of the Chemical Society, Faraday Transactions 1, vol. 84, no. 8, pp. 2855-2873, 1988.

[67] V. A. Roginsky, L. M. Pisarenko, W. Bors, C. Michel, and M. Saran, "Comparative pulse radiolysis studies of alkyl- and methoxy-substituted semiquinones formed from quinones and hydroquinones," Journal of the Chemical Society, Faraday Transactions, vol. 94, no. 13, pp. 1835-1840, 1998.

[68] M. N. Schuchmann, E. Bothe, J. Von Sonntag, and C. Von Sonntag, "Reaction of $\mathrm{OH}$ radicals with benzoquinone in aqueous solutions. A pulse radiolysis study," Journal of the Chemical Society. Perkin Transactions 2, no. 4, pp. 791-796, 1998.

[69] D. Meisel and P. Neta, "One-electron redox potentials of nitro compounds and radiosensitizers. Correlation with spin densities of their radical anions," Journal of the American Chemical Society, vol. 97, no. 18, pp. 5198-5203, 1975.

[70] S. I. Bailey and I. M. Ritchie, "A cyclic voltammetric study of the aqueous electrochemistry of some quinones," Electrochimica Acta, vol. 30, no. 1, pp. 3-12, 1985.

[71] S. I. Bailey, I. M. Ritchie, and F. R. Hewgill, "The construction and use of potential-pH diagrams in organic oxidationreduction reactions," Journal of the Chemical Society, Perkin Transactions 2, no. 5, pp. 645-652, 1983.

[72] G. M. Rao, J. W. Lown, and J. A. Plambeck, "Electrochemical studies of antitumor antibiotics. III. Daunorubicin and adriamycin," Journal of the Electrochemical Society, vol. 125, no. 4, pp. 534-539, 1978.

[73] C. Molinier-Jumel, B. Malfoy, J. A. Reynaud, and G. AubelSadron, "Electrochemical study of DNA-anthracyclines interaction," Biochemical and Biophysical Research Communications, vol. 84, no. 2, pp. 441-449, 1978.
[74] R. P. Baldwin, D. Packett, and T. M. Woodcock, "Electrochemical behavior of adriamycin at carbon paste electrodes," Analytical Chemistry, vol. 53, no. 3, pp. 540-542, 1981.

[75] E. N. Chaney Jr. and R. P. Baldwin, "Electrochemical determination of adriamycin compounds in urine by preconcentration at carbon paste electrodes," Analytical Chemistry, vol. 54, no. 14, pp. 2556-2560, 1982.

[76] K. Kano, T. Konse, N. Nishimura, and T. Kubota, "Electrochemical properties of adriamycin adsorbed on a mercury electrode surface," Bulletin of the Chemical Society of Japan, vol. 57, no. 9, pp. 2383-2390, 1984.

[77] P. S. Guin, S. Das, and P. C. Mandal, "Electrochemical reduction of sodium 1,4-dihydroxy-9,10-anthraquinone-2sulphonate in aqueous and aqueous dimethyl formamide mixed solvent: a cyclic voltammetric study," International Journal of Electrochemical Science, vol. 3, no. 9, pp. 10161028, 2008.

[78] S. G. Mairanovskii, Catalytic and kinetic Waves in Polarography, Plenum Press, New York, NY, USA, 1968.

[79] I. Tachi, Polarography, Iswanami, Tokyo, Japan, 1954.

[80] Y. Hahn and H. Y. Lee, "Electrochemical behavior and square wave voltammetric determination of doxorubicin hydrochloride," Archives of Pharmacal Research, vol. 27, no. 1, pp. 31-34, 2004.

[81] D. A. El-Hady, M. I. Abdel-Hamid, M. M. Seliem, and N. A. E-Maali, "Voltammetric studies of $\mathrm{Cu}$-adriblastina complex and its effect on ssDNA-adriblastina interaction at in situ mercury film electrode," Archives of Pharmacal Research, vol. 27, no. 11, pp. 1161-1167, 2004.

[82] S. Zhang, K. Wu, and S. Hu, "Carbon paste electrode based on surface activation for trace adriamycin determination by a preconcentration and voltammetric method," Analytical Sciences, vol. 18, no. 10, pp. 1089-1092, 2002.

[83] J. Hu and Q. Li, "Voltammetric behavior of adriamycin and its determination at Ni ion-implanted electrode," Analytical Sciences, vol. 15, no. 12, pp. 1215-1218, 1999.

[84] V. Kertesz, J. Q. Chambers, and A. N. Mullenix, "Chronoamperometry of surface-confined redox couples. Application to daunomycin adsorbed on hanging mercury drop electrodes," Electrochimica Acta, vol. 45, no. 7, pp. 1095-1104, 1999.

[85] C. Yi and M. Gratzl, "Continuous in situ electrochemical monitoring of doxorubicin efflux from sensitive and drugresistant cancer cells," Biophysical Journal, vol. 75, no. 5, pp. 2255-2261, 1998.

[86] R. Gill and H. I. Stonehill, "A polarographic investigation of the tautomerism of 2-hydroxy- and 2: 6-dihydroxyanthraquinol," Journal of the Chemical Society (Resumed), pp. 1845-1857, 1952.

[87] N. H. Furman and K. G. Stone, "A polarographic study of certain anthraquinones," Journal of the American Chemical Society, vol. 70, no. 9, pp. 3055-3061, 1948.

[88] P. S. Guin, S. Das, and P. C. Mandal, "Sodium 1, 4-dihydroxy9, 10-anthraquinone- 2-sulphonate interacts with calf thymus DNA in a way that mimics anthracycline antibiotics: an electrochemical and spectroscopic study," Journal of Physical Organic Chemistry, vol. 23, no. 6, pp. 477-482, 2010.

[89] F. C. Anson and B. Epstein, "A chronocoulometric study of the adsorption of anthraquinone monosulfonate on mercury," Journal of The Electrochemical Society, vol. 115, no. 11, pp. 1155-1158, 1968. 
[90] J. P. O'Kelly and R. J. Forster, "Potential dependent adsorption of anthraquinone-2,7-disulfonate on mercury," Analyst, vol. 123, pp. 1987-1993, 1998.

[91] H. Berg, "“Irreversible" anthrachinone," Die Naturwissenschaften, vol. 48 , no. 23 , p. $714,1961$.

[92] K.-K. Shiu, F. Song, and H.-P. Dai, "Potentiometric pH sensor with anthraquinone sulfonate adsorbed on glassy carbon electrodes," Electroanalysis, vol. 8, no. 12, pp. 1160-1164, 1996.

[93] H. Kahlert, "Functionalized carbon electrodes for $\mathrm{pH}$ determination," Journal of Solid State Electrochemistry, vol. 12, no. 10, pp. 1255-1266, 2008.

[94] K. Shi and K.-K. Shiu, "Adsorption of some quinone derivatives at electrochemically activated glassy carbon electrodes," Journal of Electroanalytical Chemistry, vol. 574, no. 1, pp. 63-70, 2004.

[95] T. Bechtold, R. Gutmann, E. Burtscher, and O. Bobleter, "Cyclic voltammetric study of anthraquinone-2-sulfonate in the presence of Acid Yellow 9," Electrochimica Acta, vol. 42, no. 23-24, pp. 3483-3487, 1997.

[96] M. P. Soriaga and A. T. Hubbard, "Determination of the orientation of adsorbed molecules at solid-liquid interfaces by thin-layer electrochemistry: aromatic compounds at platinum electrodes," Journal of the American Chemical Society, vol. 104, no. 10, pp. 2735-2742, 1982.

[97] M. P. Soriaga and A. T. Hubbard, "Determination of the orientation of aromatic molecules adsorbed on platinum electrodes: the influence of iodide, a surface-active anion," Journal of the American Chemical Society, vol. 104, no. 10, pp. 2742-2747, 1982.

[98] M. P. Soriaga and A. T. Hubbard, "Determination of the orientation of aromatic molecules adsorbed on platinum electrodes. The effect of solute concentration," Journal of the American Chemical Society, vol. 104, no. 14, pp. 3937-3945, 1982.

[99] M. P. Soriaga, P. H. Wilson, A. T. Hubbard, and C. S. Benton, "Orientational transitions of aromatic molecules adsorbed on platinum electrodes 1 Previous articles in this series appear in refs. 1-3," Journal of Electroanalytical Chemistry, vol. 142, no. 1-2, pp. 317-336, 1982.

[100] P. He, R. M. Crooks, and L. R. Faulkner, "Adsorption and electrode reactions of disulfonated anthraquinones at mercury electrodes," Journal of Physical Chemistry, vol. 94, no. 3, pp. 1135-1141, 1990.

[101] W. E. Turner and P. T. Elving, "Electrochemical behavior of the quinone-hydroquinone system in pyridine," Journal of The Electrochemical Society, vol. 112, no. 12, pp. 1215-1217, 1965.

[102] V. J. Koshy, V. Sawayambunathan, and N. Periasamy, "A reversible redox couple in quinone-hydroquinone system in nonaqueous medium," Journal of the Electrochemical Society, vol. 127, no. 12, pp. 2761-2763, 1980.

[103] M. P. Soriaga, J. H. White, and A. T. Hubbard, "Orientation of aromatic compounds adsorbed on platinum electrodes. The effect of temperature," Journal of Physical Chemistry, vol. 87, no. 16, pp. 3048-3054, 1983.

[104] M. P. Soriaga, J. L. Stickney, and A. T. Hubrard, "Electrochemical oxidation of aromatic compounds adsorbed on platinum electrodes. The influence of molecular orientation," Journal of Electroanalytical Chemistry, vol. 144, no. 1-2, pp. 207-215, 1983.

[105] A. T. Hubbard, J. L. Stickney, M. P. Soriaga et al., "Electrochemical processes at well-defined surfaces," Journal of Electroanalytical Chemistry, vol. 168, no. 1-2, pp. 43-66, 1984.
[106] M. P. Soriaga, E. Binamira-Soriaga, A. T. Hubbard, J. B. Benziger, and K. W. P. Pang, "Surface coordination chemistry of platinum studied by thin-layer electrodes. Adsorption, orientation, and mode of binding of aromatic and quinonoid compounds," Inorganic Chemistry, vol. 24, no. 1, pp. 65-73, 1985.

[107] S. W. Han, T. H. Ha, C. H. Kim, and K. Kim, "Self-assembly of anthraquinone-2-carboxylic acid on silver: Fourier transform infrared spectroscopy, ellipsometry, quartz crystal microbalance, and atomic force microscopy study," Langmuir, vol. 14, no. 21, pp. 6113-6120, 1998.

[108] S. W. Han, S. W. Joo, T. H. Ha, Y. Kim, and K. Kirn, "Adsorption characteristics of anthraquinone-2-carboxylic acid on gold," Journal of Physical Chemistry B, vol. 104, no. 50, pp. 11987-11995, 2000.

[109] A. J. Bard and L. R. Faulkner, Electrochemical Methods, John Wiley \& Sons, 2nd edition, 2000.

[110] N. Gupta and H. Linschitz, "Hydrogen-bonding and protonation effects in electrochemistry of quinones in aprotic solvents," Journal of the American Chemical Society, vol. 119, no. 27, pp. 6384-6391, 1997.

[111] A. Capon and R. Parsons, "The rate of a simple electron exchange reaction as a function of the electrode material," Journal of Electroanalytical Chemistry, vol. 46, no. 2, pp. 215-222, 1973.

[112] D. H. Evans, in Encyclopedia of Electrochemistry of the Elements, A. J. Bard and H. Lund, Eds., vol. 12, Marcel Dekker, New York, NY, USA, 1978.

[113] R. D. Rieke, T. Saji, and N. Kujundzic, "Electrochemical studies of methyl substituted 1,4-quinones. Part I. The electrochemical dimerization of duroquinone," Journal of Electroanalytical Chemistry, vol. 102, no. 3, pp. 397-405, 1979.

[114] M. D. Stallings, M. M. Morrison, and D. T. Sawyer, "Redox chemistry of metal-catechol complexes in aprotic media. 1. Electrochemistry of substituted catechols and their oxidation products," Inorganic Chemistry, vol. 20, no. 8, pp. 2655-2660, 1981.

[115] C. Rüssel and W. Janicke, "Heterogeneous electron exchange of quinones in aprotic solvents. Part III. The second reduction step of p-benzoquinone and its dependence on the supporting electrolyte," Journal of Electroanalytical Chemistry, vol. 199, no. 1, pp. 139-151, 1986.

[116] M. Oyama, T. Hoshino, and S. Okazaki, "Solvent effect on the ion pair formation between 2,3,5,6-tetrachloro-1,4benzoquinone anion radical and $\mathrm{Mg}$ measured using a pulse electrolysis stopped flow method," Journal of Electroanalytical Chemistry, vol. 401, no. 1-2, pp. 243-246, 1996.

[117] M. Oyama, R. D. Webster, M. Suárez, F. Marken, R. G. Compton, and S. Okazaki, "Mechanistic aspects of the electrochemical reduction of 7,7,8,8-tetracyanoquinodimethane in the presence of Mg or Ba," Journal of Physical Chemistry B, vol. 102, no. 34, pp. 6588-6595, 1998.

[118] M. Oyama, F. Marken, R. D. Webster, J. A. Cooper, R. G. Compton, and S. Okazaki, "Ion pair formation between the electrogenerated 2,3-dichloro-5,6-dicyano-1,4benzoquinone dianion and the sodium ion at platinum surfaces," Journal of Electroanalytical Chemistry, vol. 451, no. 1-2, pp. 193-201, 1998.

[119] S. U. Pedersen, T. B. Christensen, T. Thomasen, and K. Daasbjerg, "New methods for the accurate determination of extinction and diffusion coefficients of aromatic and heteroaromatic radical anions in N,N-dimethylformamide," Journal of Electroanalytical Chemistry, vol. 454, no. 1-2, pp. 123-143, 1998. 
[120] M. Aguilar-Martinez, G. Cuevas, M. Jimenez-Estrada, I. Gonzalez, B. Lotina- Hennsen, and N. Macias-Ruvalcaba, "An experimental and theoretical study of the substituent effects on the redox properties of 2-[(R-phenyl)-amine]1,4-naphthalenediones in acetonitrile," Journal of Organic Chemistry, vol. 64, no. 10, pp. 3684-3694, 1999.

[121] M. Shamsipur, A. Siroueinejad, B. Hemmateenejad et al., "Cyclic voltammetric, computational, and quantitative structure-electrochemistry relationship studies of the reduction of several 9,10-anthraquinone derivatives," Journal of Electroanalytical Chemistry, vol. 600, no. 2, pp. 345-358, 2007.

[122] M. W. Lehmann and D. H. Evans, "Anomalous behavior in the two-step reduction of quinones in acetonitrile," Journal of Electroanalytical Chemistry, vol. 500, no. 1-2, pp. 12-20, 2001.

[123] T. Fujinaga, K. Izutsu, and T. Nomura, "Effect of metal ions on the polarographic reduction of organic compounds in dipolar aprotic solvents," Journal of Electroanalytical Chemistry, vol. 29, no. 1, pp. 203-209, 1971.

[124] J. Johnson, I. Gandhidasan, and R. Murugesan, "Cytotoxicity and superoxide anion generation by some naturally occurring quinones," Free Radical Biology and Medicine, vol. 26, no. 9-10, pp. 1072-1078, 1999.

[125] N. U. Frigaard, S. Tokita, and K. Matsuura, "Exogenous quinones inhibit photosynthetic electron transfer in Chloroflexus aurantiacus by specific quenching of the excited bacteriochlorophyll c antenna," Biochimica et Biophysica Acta, vol. 1413, no. 3, pp. 108-116, 1999.

[126] J. J. Inbaraj, M. C. Krishna, R. Ganghidasan, and R. Murugesen, "Cytotoxicity, redox cycling and photodynamic action of two naturally occurring quinones," Biochimica et Biophysica Acta, vol. 1472, pp. 462-470, 1999.

[127] N. Watanabe and H. J. Forman, "Autoxidation of extracellular hydroquinones is a causative event for the cytotoxicity of menadione and DMNQ in A549-S cells," Archives of Biochemistry and Biophysics, vol. 411, no. 1, pp. 145-157, 2003.

[128] N. R. Bachur, S. L. Gordon, and M. V. Gee, "A general mechanism for microsomal activation of quinone anticancer agents to free radicals," Cancer Research, vol. 38, no. 6, pp. 1745-1750, 1978.

[129] I. Piljac and R. W. Murray, "Nonaqueous electrochemistry of 1-hydroxy-9,10-anthraquinone and its conjugate base," Journal of The Electrochemical Society, vol. 118, no. 11, pp. 1758-1764, 1971.

[130] F. J. González, J. M. Aceves, R. Miranda, and I. González, "The electrochemical reduction of perezone in the presence of benzoic acid in acetonitrile," Journal of Electroanalytical Chemistry, vol. 310, no. 1-2, pp. 293-303, 1991.

[131] M. Aguilar-Martínez, J. A. Bautista-Martínez, N. MacíasRuvalcaba et al., "Molecular structure of substituted phenylamine $\alpha$-OMe- and $\alpha$-OH-p-benzoquinone derivatives. Synthesis and correlation of spectroscopic, electrochemical, and theoretical parameters," Journal of Organic Chemistry, vol. 66, no. 25, pp. 8349-8363, 2001.

[132] R. L. Blankespoor, R. Hsung, and D. L. Schutt, "Electroreductive cleavage of substituted 9,10-anthraquinones in 50\% aqueous THF buffers: a pH-dependent process," Journal of Organic Chemistry, vol. 53, no. 13, pp. 3032-3035, 1988.

[133] D. O. Wipf, K. R. Wehmeyer, and R. Mark Wightman, "Disproportionation of quinone radical anions in protic solvents at high pH," Journal of Organic Chemistry, vol. 51, no. 25 , pp. $4760-4764,1986$.
[134] A. J. Fry and R. G. Reed, "The electrochemical reduction of imines in dimethylformamide," Journal of the American Chemical Society, vol. 91, no. 23, pp. 6448-6451, 1969.

[135] E. Buncel and E. A. Symon, "The H-acidity function for dimethylformamide-water," Canadian Journal of Chemistry, vol. 48, no. 21, pp. 3354-3357, 1970.

[136] X. Zheng, W. A. Tao, and R. G. Cooks, "Gas-phase S2 reactivity of dicoordinated borinium cations using pentaquadrupole mass spectrometry," Journal of the American Society for Mass Spectrometry, vol. 12, no. 8, pp. 948-955, 2001.

[137] F. C. Anson, "Innovations in the study of adsorbed reactants by chronocoulometry," Analytical Chemistry, vol. 38, no. 1, pp. 54-57, 1966.

[138] J. Koyama, I. Morita, N. Kobayashi et al., "Correlation of redox potentials and inhibitory effects on Epstein-Barr virus activation of 2-azaanthraquinones," Cancer Letters, vol. 212, no. 1, pp. 1-6, 2004.

[139] Y. B. Shim and SU. M. Park, "Spectroelectrochemical studies of p-benzoquinone reduction in aqueous media," Journal of Electroanalytical Chemistry, vol. 425, no. 1-2, pp. 201-207, 1997.

[140] H. Park, MI. S. Won, C. Cheong, and Y. B. Shim, "In-situ ESR detection of radical species of p-benzoquinone in aqueous media," Electroanalysis, vol. 14, no. 21, pp. 1501-1507, 2002.

[141] R. J. Forster and J. P. O'Kelly, "Protonation reactions of anthraquinone-2,7-disulphonic acid in solution and within monolayers," Journal of Electroanalytical Chemistry, vol. 498, no. 1-2, pp. 127-135, 2001.

[142] Y. Tang, Y. Wu, and Z. Wang, "Spectroelectrochemistry for electroreduction of p-benzoquinone in unbuffered aqueous solution," Journal of the Electrochemical Society, vol. 148, no. 4, pp. E133-E138, 2001.

[143] M. Quan, D. Sanchez, M. F. Wasylkiw, and D. K. Smith, "Voltammetry of quinones in unbuffered aqueous solution: reassessing the roles of proton transfer and hydrogen bonding in the aqueous electrochemistry of quinones," Journal of the American Chemical Society, vol. 129, no. 42, pp. 12847-12856, 2007.

[144] O. H. Müller, "Oxidation-reduction potentials measured with the dropping mercury electrode. III. Polarographic study of quinhydrone in buffered and unbuffered solutions," Journal of the American Chemical Society, vol. 62, no. 9, pp. 2434-2441, 1940.

[145] I. M. Kolthoff and E. F. Orlemann, "The use of the dropping mercury electrode as an indicator electrode in poorly poised systems," Journal of the American Chemical Society, vol. 63, no. 3, pp. 664-667, 1941.

[146] J. C. Abbott and J. W. Collat, "Indirect polarographic determination of acids," Analytical Chemistry, vol. 35, no. 7, pp. 859-863, 1963.

[147] R. T. Robertson and B. D. Pendley, "Microelectrodes as probes in low electrolyte solutions: the reduction of quinone in aqueous sulfuric acid solution," Journal of Electroanalytical Chemistry, vol. 374, no. 1-2, pp. 173-177, 1994.

[148] Y. Sato, M. Fujita, F. Mizutani, and K. Uosaki, "Electrochemical properties of the 2-mercaptohydroquinone monolayer on a gold electrode. Effect of solution $\mathrm{pH}$, adsorption time and concentration of the modifying solution," Journal of Electroanalytical Chemistry, vol. 409, no. 1-2, pp. 145-154, 1996.

[149] G. March, S. Reisberg, B. Piro et al., "Electrochemical kinetic analysis of a 1,4-hydroxynaphthoquinone self-assembled monolayer," Journal of Electroanalytical Chemistry, vol. 622, no. 1, pp. 37-43, 2008. 
[150] M. F. Marcus and M. D. Hawley, "Electrochemical studies of the redox behavior of $\alpha$-tocopherylquinone and a related model quinone," Biochimica et Biophysica Acta, vol. 222, no. 1, pp. 163-173, 1970.

[151] A. Ashnagar, J. M. Bruce, P. L. Dutton, and R. C. Prince, "One- and two-electron reduction of hydroxy-1,4-naphthoquinones and hydroxy-9,10-anthraquinones. The role of internal hydrogen bonding and its bearing on the redox chemistry of the anthracycline antitumour quinones," Biochimica et Biophysica Acta, vol. 801, no. 3, pp. 351-359, 1984.

[152] J. Tonholo, L. R. Freitas, F. C. De Abreu et al., "Electrochemical properties of biologically active heterocyclic naphthoquinones," Journal of the Brazilian Chemical Society, vol. 9, no. 2, pp. 163-169, 1998.

[153] T. D. Chung, D. Choi, S. K. Kang, S. K. Lee, S. K. Chang, and H. Kim, "Electrochemical behavior of calix[4]arenediquinones and their cation binding properties," Journal of Electroanalytical Chemistry, vol. 396, no. 1-2, pp. 431-439, 1995.

[154] H. Lund and M. M. Baizer, Organic Electrochemistry, Marcel Dekker, New York, NY, USA, 3rd edition, 1991.

[155] C. Frontana, B. A. Frontana-Uribe, and I. González, "Electrochemical and ESR study on the transformation processes of $\alpha$-hydroxy-quinones," Journal of Electroanalytical Chemistry, vol. 573, no. 2, pp. 307-314, 2004.

[156] S. Itoh, H. Kawakami, and S. Fukuzumi, "Electrochemical behavior and characterization of semiquinone radical anion species of coenzyme PQQ in aprotic organic media," Journal of the American Chemical Society, vol. 120, no. 29, pp. 7271-7277, 1998.

[157] M. E. Bodini, P. E. Bravo, and V. Aranciba, "Voltammetric and spectroscopic study of the iron(II) complexes with the semiquinone of 2-hydroxy-1,4-naphthoquinone (lawsone) in aprotic medium," Polyhedron, vol. 13, no. 3, pp. 497-503, 1994.

[158] M. E. Bodini and V. Arancibia, "Manganese complexes with 2-hydroxy-3(3-methyl-2-butenyl)-1,4-naphthoquinone (Lapachol). Redox chemistry and spectroscopy in dimethylsulphoxide," Polyhedron, vol. 8, no. 11, pp. 1407-1412, 1989.

[159] M. O. F. Goulart, N. M. F. Lima, A. E. G. Sant'Ana et al., "Electrochemical studies of isolapachol with emphasis on oxygen interaction with its radical anions," Journal of Electroanalytical Chemistry, vol. 566, no. 1, pp. 25-29, 2004.

[160] F. J. González, "Cyclic voltammetry of two analogue K-group vitamin compounds in dimethylsulfoxide," Electroanalysis, vol. 10, no. 9, pp. 638-642, 1998.

[161] J. A. Bautista-Martínez, I. González, and M. AguilarMartínez, "Correlation of voltammetric behavior of $\alpha$-hydroxy and $\alpha$-methoxy quinones with the change of acidity level in acetonitrile," Journal of Electroanalytical Chemistry, vol. 573, no. 2, pp. 289-298, 2004.

[162] T. Ossowski, P. Pipka, A. Liwo, and D. Jeziorek, "Electrochemical and UV-spectrophotometric study of oxygen and superoxide anion radical interaction with anthraquinone derivatives and their radical anions," Electrochimica Acta, vol. 45, no. 21, pp. 3581-3587, 2000.

[163] C. Frontana and I. González, "The role of intramolecular hydrogen bonding in the electrochemical behavior of hydroxy-quinones and in semiquinone stability," Journal of the Brazilian Chemical Society, vol. 16, no. 3A, pp. 299-307, 2005.
[164] P. W. Crawford, E. Carlos, J. C. Ellegood et al., "The electrochemistry of antineoplastic furanquinones: electrochemical properties of benzo[b]naphtho[2,3-d]furan-6,11dione derivatives," Electrochimica Acta, vol. 41, no. 15, pp. 2399-2403, 1996.

[165] M. Gómez, F. J. González, and I. González, "Intra and intermolecular hydrogen bonding effects in the electrochemical reduction of $\alpha$-phenolic-naphthoquinones," Journal of Electroanalytical Chemistry, vol. 578, no. 2, pp. 193-202, 2005.

[166] H. Weiss, T. Friedrich, G. Hofhaus, and D. Preis, "The respiratory-chain $\mathrm{NADH}$ dehydrogenase (complex I) of mitochondria," European Journal of Biochemistry, vol. 197, no. 3, pp. 563-576, 1991.

[167] C. -Y. Li and J. Jenq, "Kinetic study of one-electron reduction of aromatic quinones with aminoalkylamino side chains in $\mathrm{N}, \mathrm{N}$-dimethylformamide by square wave voltammetry and allied techniques," Electrochimica Acta, vol. 36, no. 2, pp. 269-276, 1991.

[168] P. W. Crawford, J. Gross, K. Lawson et al., "Electrochemical properties of some biologically active quinone derivatives: furanquinones, pyridoquinones, and diplamine, a cytotoxic pyridoacridine alkaloid," Journal of the Electrochemical Society, vol. 144, no. 11, pp. 3710-3715, 1997.

[169] M. Salas, M. Gómez, F. J. González, and B. Gordillo, "Electrochemical reduction of 1,4-benzoquinone. Interaction with alkylated thymine and adenine nucleobases," Journal of Electroanalytical Chemistry, vol. 543, no. 1, pp. 73-81, 2003.

[170] J. A. Bautista-Martínez, I. González, and M. AguilarMartínez, "Influence of acidity level in acetonitrile on Hammett-Zuman type correlations on the reduction of $\alpha$-hydroxyquinones," Electrochimica Acta, vol. 48, no. 28, pp. 4239-4244, 2003.

[171] B. R. Eggins and J. Q. Chambers, "Proton effects in the electrochemistry of the quinone hydroquinone system in aprotic solvents," Journal of The Electrochemical Society, vol. 117, no. 2, pp. 186-192, 1970.

[172] K. Takamura and Y. Hayakawa, "Effects of proton donors on the polarographic reduction of methyl-p-benzoquinone in aqueous and methyl cellosolve solutions," Journal of Electroanalytical Chemistry, vol. 31, no. 1, pp. 225-232, 1971.

[173] J. Kim, T. D. Chung, and H. Kim, "Determination of biologically active acids based on the electrochemical reduction of quinone in acetonitrile + water mixed solvent," Journal of Electroanalytical Chemistry, vol. 499, no. 1, pp. 78-84, 2001.

[174] M. Gómez, I. González, F. J. González, R. Vargas, and J. Garza, "The association of neutral systems linked by hydrogen bond interactions: a quantitative electrochemical approach," Electrochemistry Communications, vol. 5, no. 1, pp. 12-15, 2003.

[175] Y. -O. Kim, Y. M. Jung, S. B. Kim, B. H. Hong, K. S. Kim, and S. -M. Park, "Mechanistic study on electrochemical reduction of calix[4] quinone in acetonitrile containing water," Journal of Physical Chemistry B, vol. 108, no. 15, pp. 4927-4936, 2004.

[176] C. Amatore, M. Gareil, and J. M. Saveeant, "Homogeneous versus heterogeneous electron transfer in electrochemical reactions: Application to the electrohydrogenation of anthracene and related reactions," Journal of Electroanalytical Chemistry, vol. 147, pp. 1-38, 1983.

[177] M. Gómez-Kaifer, P. A. Reddy, C. D. Gutsche, and L. Echegoyen, "Electroactive calixarenes. 1. Redox and cation binding properties of calixquinones," Journal of the American Chemical Society, vol. 116, no. 8, pp. 3580-3587, 1994. 
[178] K. Suga, M. Fujihira, Y. Morita, and T. Agawa, "Electrochemical study on calix[4]quinone and calix[4]hydroquinone in N,N-dimethylformamide," Journal of the Chemical Society, Faraday Transactions, vol. 87, no. 10, pp. 1575-1578, 1991.

[179] A. Casnati, E. Comelli, M. Fabbi et al., "Synthesis, conformations and redox properties of diametrical calix[4]arenediquinones," Recueil des Travaux Chimiques des Pays-Bas, vol. 112, no. 6, pp. 384-392, 1993.

[180] M. W. Lehmann and D. H. Evans, "Mechanism of the electrochemical reduction of 3,5-di-tert-butyl-1,2benzoquinone. Evidence for a concerted electron and proton transfer reaction involving a hydrogen-bonded complex as reactant," Journal of Physical Chemistry B, vol. 105, no. 37, pp. 8877-8884, 2001.

[181] C. J. H. Schutte, S. O. Paul, and R. Smit, "An ab initio study of the molecular structures of 1,4,5,8-naphthalenetetrone and 5,8-dihydroxy-1,4-naphthoquinone," Journal of Molecular Structure, vol. 297, no. C, pp. 235-241, 1993.

[182] J. R. de la Vega, J. H. Busch, J. Herman Schauble, K. L. Kunze, and B. E. Haggert, "Symmetry and tunneling in the intramolecular proton exchange in naphthazarin, methylnaphthazarin, and dimethylnaphthazarins," Journal of the American Chemical Society, vol. 104, no. 12, pp. 3295-3299, 1982.

[183] M. Takasuka and Y. Matsui, "Experimental observations and $\mathrm{CNDO} / 2$ calculations for hydroxy stretching frequency shifts, intensities, and hydrogen bond energies of intramolecular hydrogen bonds in ortho-substituted phenols," Journal of the Chemical Society, Perkin Transactions 2, no. 12, pp. 1743-1750, 1979.

[184] P. J. O’Malley, “Density functional calculated spin densities and hyperfine couplings for hydrogen bonded 1,4naphthosemiquinone and phyllosemiquinone anion radicals: a model for the A free radical formed in Photosystem I," Biochimica et Biophysica Acta, vol. 1411, no. 1, pp. 101-113, 1999.

[185] C. Sieiro, A. Sanchez, P. Crouigneau, and C. Lamy, "In situ electrochemical reduction of some naphthazarin derivatives. An electron spin resonance and INDO study," Journal of the Chemical Society, Perkin Transactions 2, no. 9, pp. 1069-1073, 1982.

[186] J. Gendell, W. R. Miller, and G. K. Fraenkel, "Electron spin resonance studies of hydroxysemiquinone radicals. Hydrogen-deuterium isotope effects in intramolecular hydrogen bonds," Journal of the American Chemical Society, vol. 91, no. 16, pp. 4369-4380, 1969.

[187] M. S. Khan and Z. H. Khan, "Ab initio and semiempirical study of structure and electronic spectra of hydroxy substituted naphthoquinones," Spectrochimica Acta A, vol. 61, no. 4, pp. 777-790, 2005.

[188] P. A. L. Ferraz, F. C. De Abreu, A. V. Pinto, V. Glezer, J. Tonholo, and M. O. F. Goulart, "Electrochemical aspects of the reduction of biologically active 2-hydroxy-3-alkyl-1,4naphthoquinones," Journal of Electroanalytical Chemistry, vol. 507, no. 1-2, pp. 275-286, 2001.

[189] F. C. Abreu, M. O. F. Goulart, and A. M. Oliveira Brett, "Reduction of lapachones in aqueous media at a glassy carbon electrode," Electroanalysis, vol. 14, no. 1, pp. 29-34, 2002.

[190] A. M. Oliveira-Brett, M. O. F. Goulart, and F. C. Abreu, "Reduction of lapachones and their reaction with Lcysteine and mercaptoethanol on glassy carbon electrodes," Bioelectrochemistry, vol. 56, no. 1-2, pp. 53-55, 2002.
[191] B. Frydman, L. J. Marton, J. S. Sun et al., "Induction of DNA topoisomerase II-mediated DNA cleavage by $\beta$-lapacphone and related naphthoquinones," Cancer Research, vol. 57, no. 4, pp. 620-627, 1997.

[192] K. Neder, L. J. Marton, L. F. Liu, and B. Frydman, "Reaction of beta-lapachone and related naphthoquinones with 2mercaptoethanol: a biomimetic model of topoisomerase II poisoning by quinones," Cellular and Molecular Biology, vol. 44, no. 3, pp. 465-474, 1998.

[193] S. Hayano and M. Fujihira, "The effect of water on the reduction potentials of some aromatic compounds in the DMF-water system," Bulletin of the Chemical Society of Japan, vol. 44, no. 8, pp. 2051-2055, 1971.

[194] M. Gómez, F. J. González, and I. González, “A model for characterization of successive hydrogen bonding interactions with electrochemically generated charged species. The quinone electroreduction in the presence of donor protons," Electroanalysis, vol. 15, no. 7, pp. 635-645, 2003.

[195] M. Gómez, F. J. González, and I. González, "Effect of host and guest structures on hydrogen bonding association influence on stoichiometry and equilibrium constants," Journal of the Electrochemical Society, vol. 150, no. 11, pp. E527-E534, 2003.

[196] I. M. Kolthoff and T. B. Reddy, "Polarography and voltammetry in dimethylsulfoxide," Journal of The Electrochemical Society, vol. 108, no. 10, pp. 980-985, 1961.

[197] M. Fujihira and S. Hayano, "The solvent effect on the visible absorption spectra of the radical anion and the dianion of anthraquinone," Bulletin of the Chemical Society of Japan, vol. 45, no. 2, pp. 644-645, 1972.

[198] P. H. Given and M. E. Peover, "Polarographic reduction of aromatic hydrocarbons and carbonyl compounds in dimethylformamide in the presence of proton-donors," Journal of the Chemical Society (Resumed), pp. 385-393, 1960.

[199] J. P. Masson, J. Devynck, and B. Trémillon, "Use of quinone systems as electrochemical $\mathrm{pH}$ indicators in anhydrous hydrogen fluoride solvent I. Electrochemical behaviour of quinones in HF and in HF-water mixtures," Journal of Electroanalytical Chemistry, vol. 64, no. 2-3, pp. 175-191, 1975.

[200] M. Gómez, C. Z. Gómez-Castro, I. I. Padilla-Martínez, F. J. Martínez-Martínez, and F. J. González, "Hydrogen bonding effects on the association processes between chloranil and a series of amides," Journal of Electroanalytical Chemistry, vol. 567, no. 2, pp. 269-276, 2004.

[201] J. Bessard, G. Cauquis, and D. Serve, "Le comportement electrochemique des couples quinone-hdyroquinone a caractere basique en milieux organiques. Cas des derives polymethoxyles," Electrochimica Acta, vol. 25, no. 9, pp. 1187-1197, 1980.

[202] E. Ouziel and CH. Yarnitzky, "Electrochemical reduction of camphorquinone in DMF in the presence of a proton donor," Journal of Electroanalytical Chemistry, vol. 78, no. 2, pp. 257-270, 1977.

[203] A. C. Aten, C. Büthker, and G. J. Hoijtink, "Electron transfer to aromatic hydrocarbons at the dropping mercury electrode," Transactions of the Faraday Society, vol. 55, pp. 324-330, 1959.

[204] R. D. Rieke, T. Saji, and N. Kujundzic, "Electrochemical studies of methyl substituted 1,4-quinones. Part I. The electrochemical dimerization of duroquinone," Journal of Electroanalytical Chemistry, vol. 102, no. 3, pp. 397-405, 1979.

[205] V. Glezer, J. Stradins, J. Friemanis, and L. Baider, "The mechanism of electrochemical reduction of intramolecular charge-transfer complexes derived from 1,4-naphthoquinone," Electrochimica Acta, vol. 28, no. 1, pp. 87-95, 1983. 
[206] M. Oyama, K. Nozaki, and S. Okazaki, "Pulse-electrolysis stopped-flow method for the electrospectroscopic analysis of short-lived intermediates generated in the electrooxidation of triphenylamine," Analytical Chemistry, vol. 63, no. 14, pp. 1387-1392, 1991.

[207] F. Ammar and J. M. Savéant, "Convolution potential sweep voltammetry. II. Multistep nernstian waves," Journal of Electroanalytical Chemistry, vol. 47, no. 2, pp. 215-221, 1973.

[208] M. Noel and K. I. Vasu, Cyclic Voltammetry and Frontier of Electrochemistry, Oxford \& IBH Publishing, India, 1990.

[209] T. Nagaoka, S. Okazaki, and T. Fujinaga, "Ion-pair effects on the electroreduction of carbonyl compounds in $\mathrm{N}$,Dimethylformamide," Journal of Electroanalytical Chemistry, vol. 133, no. 1, pp. 89-99, 1982.

[210] T. Nagaoka and S. Okazaki, "Ion-pairing between anthanthrone anions and divalent metal cations and adsorption of ion-pairs on mercury electrodes in N,Ndimethylformamide," Journal of Electroanalytical Chemistry, vol. 158, no. 1, pp. 139-151, 1983.

[211] A. Kaifer, D. A. Gustowski, L. Echegoyen et al., "Electrochemical switching of lariat ethers. Survey of cation binding by neutral and reduced forms of one- and two-armed carbonand nitrogen-pivot lariat ethers," Journal of the American Chemical Society, vol. 107, no. 7, pp. 1958-1965, 1985.

[212] G. N. Kamau and J. F. Rusling, "Microelectrode voltammetry of TCNQ in aprotic solvent at low concentrations of nonreducing and reducing salts," Journal of Electroanalytical Chemistry, vol. 292, no. 1-2, pp. 187-198, 1990.

[213] P. D. Beer, Z. Chen, and P. A. Gale, "Diester-calix[4]arenediquinone complexation and electrochemical recognition of group 1 and 2, ammonium and alkyl ammonium guest cations," Tetrahedron, vol. 50, no. 3, pp. 931-940, 1994.

[214] D. Choi, T. D. Chung, S. K. Kang et al., "Electrochemical recognition of ammonium and alkali metal cations with calix[4] arenediquinone," Journal of Electroanalytical Chemistry, vol. 387, no. 1-2, pp. 133-134, 1995.

[215] M. E. Peover and J. D. Davies, "The influence of ion-association on the polarography of quinones in dimethylformamide," Journal of Electroanalytical Chemistry, vol. 6, no. 1, pp. 46-53, 1963.

[216] T. M. Krygowski, M. Lipsztajn, and Z. Galus, "Ion pair formation effects in the reversible electroreduction of nitrobenzene in N,N-dimethylformamide," Journal of Electroanalytical Chemistry, vol. 42, no. 2, pp. 261-269, 1973.

[217] T. W. Rosanske and D. H. Evans, "Rate constants for the electrode reactions of some quinones in aprotic media at platinum, gold and mercury electrodes," Journal of Electroanalytical Chemistry, vol. 72, no. 3, pp. 277-285, 1976.

[218] K. Alizadeh and M. Shamsipur, "Calculation of the two-step reduction potentials of some quinones in acetonitrile," Journal of Molecular Structure: THEOCHEM, vol. 862, no. 1-3, pp. 39-43, 2008.

[219] P. S. Guin, S. Das, and P. C. Mandal, "Studies on the formation of a complex of $\mathrm{Cu}(\mathrm{II})$ with sodium 1,4dihydroxy-9,10-anthraquinone-2-sulphonate-an analogue of the core unit of anthracycline anticancer drugs and its interaction with calf thymus DNA," Journal of Inorganic Biochemistry, vol. 103, no. 12, pp. 1702-1710, 2009.

[220] E. G. Mimnaugh, M. A. Trush, and T. E. Gram, "Stimulation by adriamycin of rat heart and liver microsomal NADPHdependent lipid peroxidation," Biochemical Pharmacology, vol. 30, no. 20, pp. 2797-2804, 1981.

[221] J. W. Lown, Anthracycline and Anthracenedione-Based Drugs, Elsevier, Amsterdam, The Netherlands, 1988.
[222] K. J. A. Davies and J. H. Doroshow, "Redox cycling of anthracyclines by cardiac mitochondria. I. Anthracycline radical formation by NADH dehydrogenase," Journal of Biological Chemistry, vol. 261, no. 7, pp. 3060-3067, 1986.

[223] J. H. Doroshow and K. J. A. Davies, "Redox cycling of anthracyclines by cardiac mitochondria. II. Formation of superoxide anion, hydrogen peroxide, and hydroxyl radical," Journal of Biological Chemistry, vol. 261, no. 7, pp. 3068-3074, 1986.

[224] J. Tarasiuk, A. Garnier-Suillerot, and E. Borowski, "Lack of competition between cytochrome $\mathrm{C}$ and anthraquinone type drugs for the reductive sites of NADH dehydrogenase," Biochemical Pharmacology, vol. 38, no. 14, pp. 2285-2289, 1989.

[225] A. Tempczyk, J. Tarasiuk, T. Ossowski, and E. Borowski, "An alternative concept for the molecular nature of the peroxidating ability of anthracycline anti-tumor antibiotics and anthracenodiones," Anti-Cancer Drug Design, vol. 2, no. 4, pp. 371-385, 1988.

[226] J. Tarasiuk, A. Liwo, S. Wojtkowiak et al., "Molecular determinants of singlet oxygen binding by anthraquinones in relation to their redox cycling activity," Anti-Cancer Drug Design, vol. 6, no. 5, pp. 399-416, 1991.

[227] D. Jeziorek, D. Dyl, A. Liwo, W. Woznicki, A. Tempczyk, and E. Borowski, "A theoretical study of the mechanism of oxygen binding by model anthraquinones I: quantum mechanical evaluation of the oxygen-binding sites of 1,4-hydroquinone," Anti-Cancer Drug Design, vol. 7, no. 6, pp. 451-461, 1992.

[228] D. Jeziorek, D. Dyl, A. Liwo, W. Woznicki, A. Tempczyk, and E. Borowski, "A theoretical study of the mechanism of oxygen binding by model anthraquinones. Part II. Quantummechanical studies of the energetics of oxygen binding to model anthraquinones," Anti-Cancer Drug Design, vol. 8, no. 3, pp. 223-235, 1993.

[229] D. Jeziorek, D. Dyl, A. Liwo, T. Ossowski, and W. Woznicki, "Enthalpy of oxygen addition to anthraquinone derivatives determines their ability to mediate NADH oxidation," Anti-Cancer Drug Design, vol. 9, no. 5, pp. 435-448, 1994.

[230] D. Jeziorek, T. Ossowski, A. Liwo, D. Dyl, M. Nowacka, and W. Woźnicki, "Theoretical and electrochemical study of the mechanism of anthraquinone-mediated one-electron reduction of oxygen: the involvement of adducts of dioxygen species to anthraquinones," Journal of the Chemical Society. Perkin Transactions 2, no. 2, pp. 229-236, 1997. 


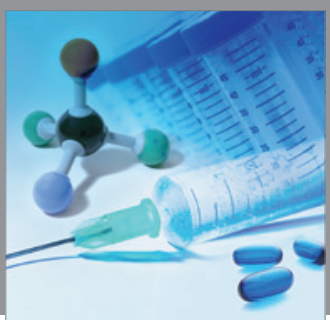

International Journal of

Medicinal Chemistry

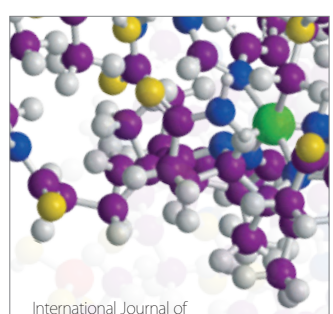

Carbohydrate Chemistry

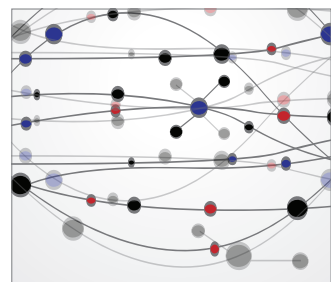

The Scientific World Journal
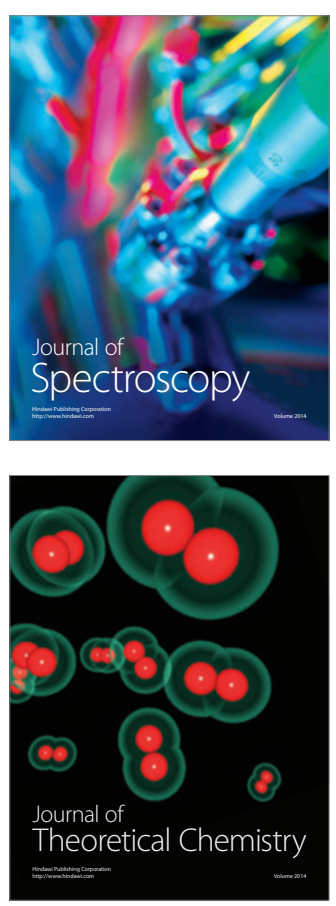
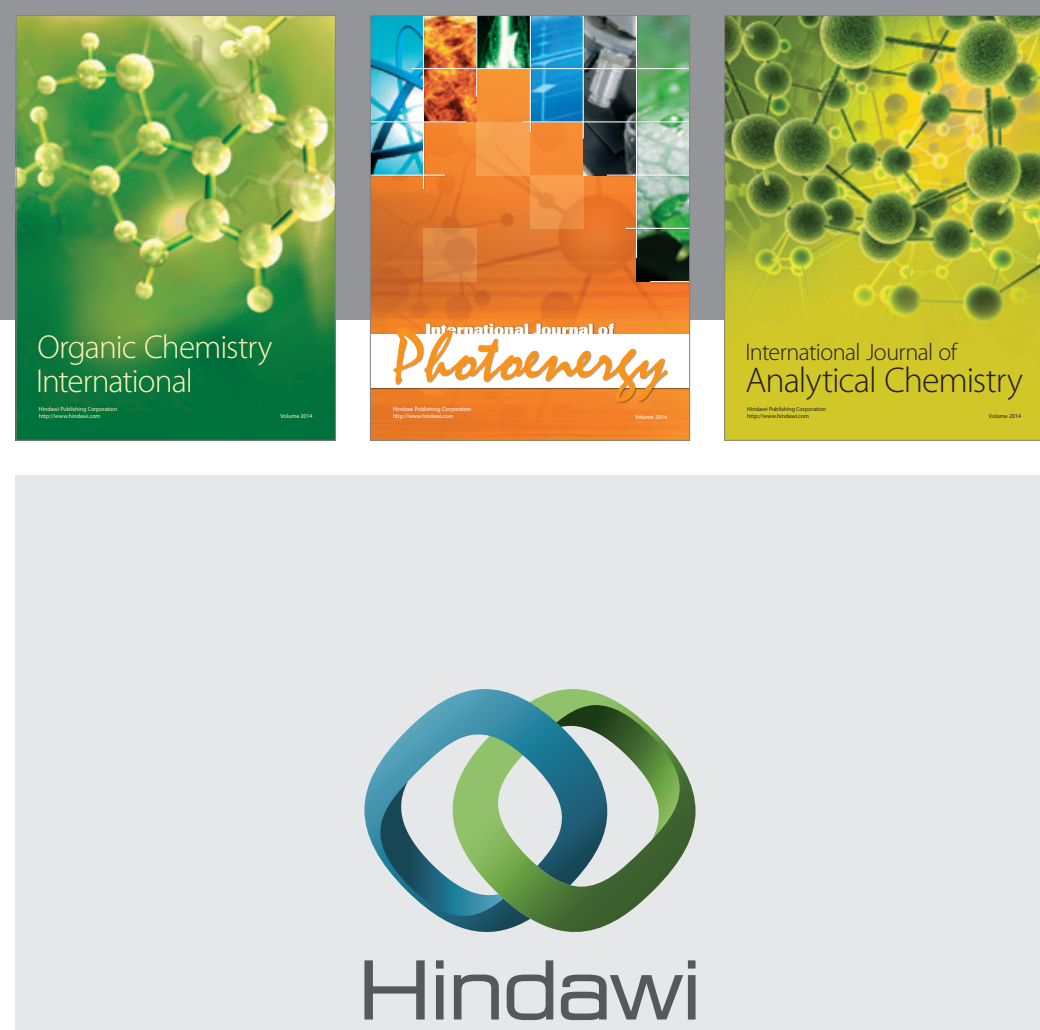

Submit your manuscripts at

http://www.hindawi.com
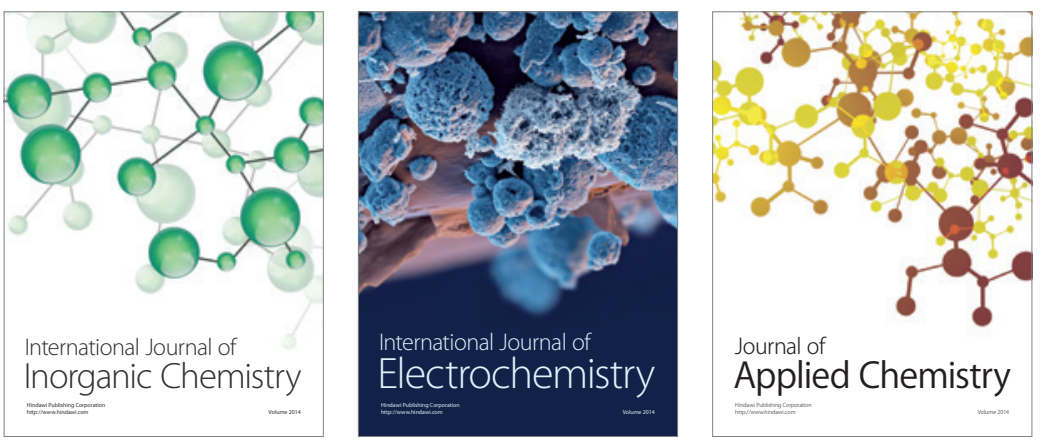

Journal of

Applied Chemistry
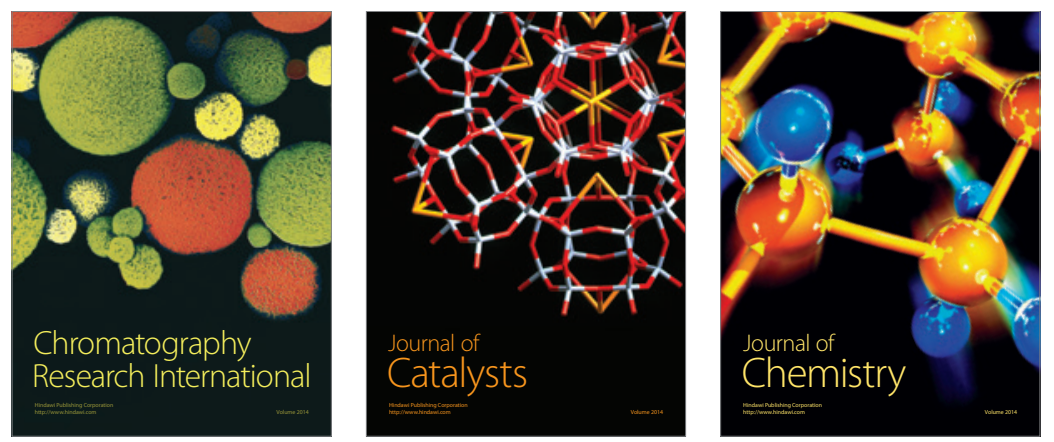
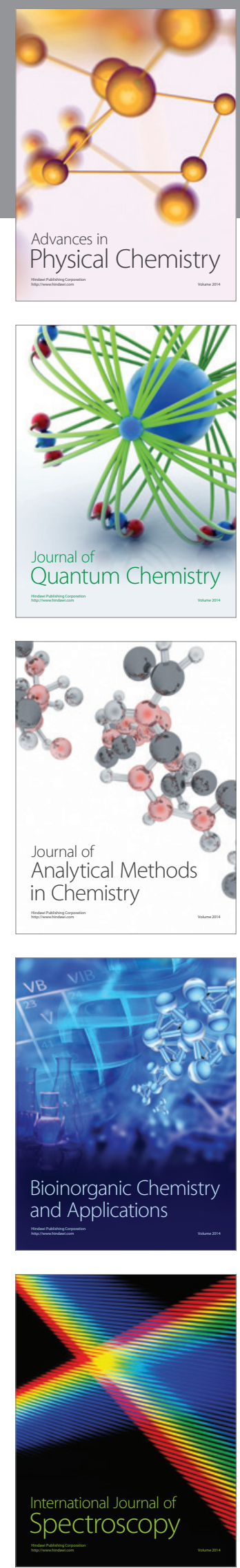